\title{
An integral and sustainable valorisation strategy of squid pen by-products
}

José Antonio Vázquez ${ }^{1 *}$, Patricia Ramos ${ }^{2}$, Jesus Valcarcel ${ }^{1}$, Luis T. Antelo ${ }^{3}$, Ramon Novoa-Carballal ${ }^{4,5}$, Rui L. Reis ${ }^{4,5}$ \& Ricardo I. Pérez-Martín ${ }^{2}$

${ }^{1}$ Grupo de Reciclado y Valorización de Materiales Residuales (REVAL), Instituto de Investigacións Mariñas (IIM-CSIC). r/ Eduardo Cabello, 6. Vigo36208. Galicia - Spain.

${ }^{2}$ Grupo de Bioquímica de Alimentos, Instituto de Investigacións Mariñas (IIMCSIC). r/ Eduardo Cabello, 6. Vigo-36208. Galicia - Spain.

${ }^{3}$ Grupo de Ingeniería de Bioprocesos, Instituto de Investigacións Mariñas (IIMCSIC). r/ Eduardo Cabello, 6. Vigo-36208. Galicia - Spain.

43B's Research Group - Biomaterials, Biodegradables and Biomimetics, University of Minho, Headquarters of the European Institute of Excellence on Tissue Engineering and Regenerative Medicine, AvePark, 4805-017 Barco, Guimarães, Portugal.

5ICVS/3B's - PT Government Associate Laboratory, Braga/Guimarães, Portugal.

*corresponding author: jvazquez@iim.csic.es 


\section{ABSTRACT}

The aim of this study was to present a sustainable valorisation approach of Loligo opalescens squid pen by-products by optimal production of chitin and chitosan biopolymers and recycling of the generated effluents. The integral recovery of squid pens started with the optimization of the deproteinization process to isolate chitin, including less hazardous enzymatic alternatives to conventional chemical treatments. Response surface methodology analysis yielded optimal conditions of $53.2^{\circ} \mathrm{C} / \mathrm{pH} 8.84$ for Alcalase, $54.7^{\circ} \mathrm{C} / \mathrm{pH} 9.16$ for Esperase and $0.2 \mathrm{M} \mathrm{NaOH} / 27.5^{\circ} \mathrm{C}$ for alkaline hydrolysis. The generated effluents were a good source of organic nitrogen (squid peptones) for the culture of a lactic acid bacterium (Pediococcus acidilactici), with biomass and metabolite productions comparable to commercial Man, Rogosa, Sharpe medium. Secondly, optimal process time and alkali concentration for the chemical deacetylation of chitin were established at $16 \mathrm{~h} / 64 \% \mathrm{NaOH}$, obtaining high purity chitosan (deacetylation degrees $>92 \%$, molecular weights $-\mathrm{Mn}$ ranging from 139 to $300 \mathrm{kDa}$ ). Optimized chitin and chitosan processes led to lower energetic costs. Alkaline effluents from chitosan production were applied as a reagent in the selective precipitation of chondroitin sulfate from enzymatic hydrolysates of shark cartilage by-products. Finally, the goodness of the proposed valorisation strategy was evaluated by developing a Material Flow Analysis.

Keywords: chitin; chitosan; Loligo opalescens pen; marine-squid peptones; integral valorisation; sustainability. 


\section{Introduction}

The genus Dorytheutis includes 8 species of squids and its distribution covers the American waters of the western Atlantic and eastern Pacific Oceans. Specifically, the habitat of the California market squid Doryteuthis opalescens (=Loligo opalescens) reaches most of the coastal waters over the continental shelf off western North America (Patrizia Jereb, 2010). L. opalescens represents the principal biomass of marine commercial species due to the decay of the anchovy fishery in the California coast (Zeidberg et al., 2006). This strain is an important fraction of the total invertebrate catch in the Northeast Pacific (Area 67) and Eastern Central Pacific (Area 77), reaching in 2010, 95000 tonnes in Area 67 and 92000 tonnes in Area 77 (FAO, 2011). However, annual catches have been decreasing in recent years achieving 39259 tonnes in 2016, the latest data recorded by FAO (FAO, 2016). Taking into account that the squid pen represents $3 \%$ of the total weight (Cortizo, 2008), it would be recover approximately 1177 tonnes of squid pen for potential production of chitin and derivatives.

Most of this squid is exported frozen to China, Japan and Europe and is used mainly for human consumption. At least $50 \%$ of the total catches are not used for food, generating 32 million tons of by-products (Arvanitoyannis and Kassaveti, 2008). There is limited information available on how the industry manages the waste of this species but it is well known that this can be transformed into products with high added value (Vázquez et al., 2017a). Squid 
pens are the most important source of $\beta$-chitin, but are currently treated as waste by the fishing industry (Lavall et al., 2007).

Chitin applications, either in its native form or chemically modified, extend to the cosmetic (Aranaz et al., 2018), food and agriculture (Hamed et al., 2016), water treatment (Yang et al., 2016), biomedical, and pharmaceutical fields (Younes and Rinaudo, 2015). Commercial chitin is almost exclusively sourced from crustacean shells, although other arthropods, molluscs, and fungi also incorporate this structural polymer. While chitin always consists of $\mathrm{N}$ acetylglucosamine units linked by $\beta-(1 \rightarrow 4)$ glycosidic bonds, the arrangement of the chains is different depending on the source. In crustaceans, the disposition of chitin chains is antiparallel ( $\alpha$-chitin), whereas the opposite happens in squid pen ( $\beta$-chitin). This leads to distinct crystal structures and related properties. Forces, both inter- and intra-molecular, are stronger in $\alpha$ - than in $\beta$-chitin, resulting in increased solubility and water absorbing capacity of squid pen $\beta$ chitin (Vázquez et al., 2013).

Weaker forces in squid pen $\beta$-chitin also carry advantages for the production of chitosan, a derivative resulting from partial deacetylation of chitin. This process allows to increase the extremely limited solubility of chitin making it more amenable for most applications. The random conversion of a sufficient number of $\mathrm{N}$-acetylglucosamine to glucosamine units renders chitosan soluble in dilute acids. Deacetylation of chitin involves alkaline hydrolysis, which appears to produce more homogeneous chitosan from squid pen $\beta$-chitin than from $\alpha$ - 
chitin, because acetyl groups are more easy accessible in the former (Domard, 2011).

From a sustainability perspective, obtaining chitin and chitosan from squid pen seems to possess certain advantages over its conventional crustacean counterparts. Crustacean shells are rich in calcium salts and caretonoid pigments, and require demineralization with diluted hydrochloric acid and oxidation of pigments (Vázquez et al., 2017b). Squid pen is not coloured and with low mineral content, rendering in most cases demineralization and blanching steps unnecessary (Chaussard and Domard, 2004).

In this context, for the evaluation of sustainable strategies of squid pen valorisation and effluents recycled, Material flow analysis (MFA) can be and adequate methodological alternative. MFA is a systematic assessment of the flows and stocks of materials within a system defined in space and time (Brunner and Rechberger, 2004). It connects the sources, the pathways, and the intermediate and final sinks of a material. This method results an attractive decision-support tool in resource, waste and environmental management since it is easy to perform by a simple material balance comparing all inputs, stocks, and outputs of a process.

The present work proposes the optimization of the deproteinization step of $L$. opalescens pen by enzymatic methods as a safer alternative to strong bases and further valorisation of the process effluents generated by microbial bioconversion. Also, the conversion of chitin into chitosan is optimized, the 
deacetylated polysaccharides are chemically characterized, and the effluents are recycled in another high-value bioproduction. All this information is processed by Material Flow Analysis (MFA) to trace the flow of raw materials through the different steps of the chitin/chitosan production process to define a valorisation strategy of effluents that will include the identification of the points where they are generated and the establishment of priorities for appropriate measures aimed at maximizing their re-use and minimizing their emission to the environment.

\section{Materials and methods}

\subsection{Pen by-products from Loligo opalescens}

Endoskeletons (pens) from L. opalescens were supplied by Cabomar S.A. (Marín, Spain) and stored at $-18^{\circ} \mathrm{C}$ until use. Initially, the pens were washed, dried in a Memmert oven model $100-800\left(55^{\circ} \mathrm{C} / 24 \mathrm{~h}\right)$, grinded in a Thermomix ${ }^{\circledR}$ TM31 and sieved using a $500 \mu \mathrm{m}$ mesh. Proximal composition of materials was performed by determination of water and ash content (AOAC, 1997), total lipids (Bligh and Dyer, 1959), total nitrogen (AOAC, 1997) and total protein as total nitrogen $\times 6.25$.

\subsection{Experimental designs for chitin and chitosan production}

Two strategies were assayed for chitin production from squid pen: chemical and enzymatic deproteinization. In both cases the experimental procedure was based on the performance of rotatable second order designs to optimize the joint effect of two independent variables (Box et al., 2005): temperature and alkali concentration for the chemical process and $\mathrm{pH}$ and temperature for 
enzymatic deproteinization. Two commercial proteases, Alcalase and Esperase, were purchased from Novozymes (Nordisk, Bagsvaerd, Denmark) and used at $1 \%$ (volume of enzyme/weight of pens, v/w). Conditions of agitation (150 rpm) and solid:liquid ratio (1:10) were maintained constant.

The variables evaluated for the conversion of chitin to chitosan were deacetylation time and $\mathrm{NaOH}$ concentration. Temperature $\left(90^{\circ} \mathrm{C}\right)$, agitation $(200$ rpm) and solid:liquid ratio (1:10) remained constant throughout the experimental development. In all plans, five replicates were realized at the centre of the experimental domain ( 0,0 in coded values). Table $\mathbf{S} 1$ (supplementary material) summarizes the codified and natural values for all designs.

Orthogonal least-squares calculation on factorial design data were used to obtain the empirical equations describing the different dependent variables assessed $(Y)$ as a function of the independent variables:

$$
Y=b_{0}+\sum_{i=1}^{n} b_{i} X_{i}+\sum_{\substack{i=1 \\ j=1}}^{n-1} \sum_{j=2}^{n} b_{i j} X_{i} X_{j}+\sum_{i=1}^{n} b_{i i} X_{i}^{2}
$$

where: $Y$ is the response evaluated, $b_{0}$ is the constant coefficient, $b_{i}$ is the coefficient of linear effect, $b_{i j}$ is the coefficient of combined effect, $b_{i i}$ is the coefficient of quadratic effect, $n$ is the number of variables and $X_{i}$ and $X_{j}$ are the independent variables studied in each case. Assumptions for mathematical modelling and statistical analysis of response surfaces were: 1) the error associated was homoscedasticity (constant variance); 2) no autocorrelation 
between observations; 3 ) type I and type II errors were avoided. The Student ttest $(\alpha=0.05)$ was used to determine the statistical significance of the coefficients and the adjusted coefficients of determination $\left(R_{a d j}^{2}\right)$ to establish the goodness-of-fit. The following mean squares ratios from Fisher $F$ test $(\alpha=0.05)$ were calculated to define model consistency: $F 1=$ Model $/$ Total error, being the model acceptable when $F 1 \geq F_{\text {den }}^{\text {num }} ; F 2=($ Model + Lack of fitting $) /$ Model, being the model acceptable when $F 2 \leq F_{\text {den }}^{\text {num }} . F_{\text {den }}^{\text {num }}$ are the theoretical values to $\alpha=0.05$ with the corresponding degrees of freedom for numerator (num) and denominator (den).

\subsection{Chemical and enzymatic hydrolysis of $L$. opalescens pens}

Chemical hydrolyses were realized in Erlenmeyer flasks (of $100 \mathrm{~mL}$ ) loaded with $5 \mathrm{~g}$ of pens and $50 \mathrm{~mL}$ of reagent $(\mathrm{NaOH})$ at the concentrations and temperatures defined in the factorial design and maintaining continuous agitation $(150 \mathrm{rpm})$ in all cases. Enzyme proteolyses were carried out in a controlled $\mathrm{pH}$-Stat system with a $100 \mathrm{~mL}$ glass-reactor (and $5 \mathrm{~g}$ of pens) under the conditions mentioned in the previous section. In both strategies at the end of the hydrolysis $(6 \mathrm{~h})$, samples were centrifuged $(3000 \mathrm{~g} / 5 \mathrm{~min})$ and filter (20 $\mu \mathrm{m})$. The solid and liquid fractions obtained were stored at $-18^{\circ} \mathrm{C}$ until analysis. The degree of hydrolysis $(\mathrm{H}$, as \%) was quantified following the $\mathrm{pH}$-Stat method (Adler-Nissen, 1986) and equations previously described (Vázquez et al., 2017c). The data of $\mathrm{H}$ over time were then modelled with Weibull equation (Vázquez et al., 2016): 


$$
H=H_{m}\left\{1-\exp \left[-\ln 2\left(\frac{t}{\tau}\right)^{\beta}\right]\right\}
$$

where, $H$ is the degree of hydrolysis (\%); $t$ the time of hydrolysis (min); $H_{m}$ the maximum degree of hydrolysis (\%); $\beta$ a parameter related with the maximum slope of muscle hydrolysis (dimensionless); and $\tau$ the time required to achieve the semi-maximum degree of hydrolysis (min).

\subsection{Chitin and protein determinations in solid and effluent fractions}

The purity of chitin (as \%) in the solids generated in the process of pen deproteinization was determined from the mass balance among protein, mineral salts and final solid recovered (Figure S1, supplementary material). In those samples, mineral salts were quantified as the content of ash obtained by calcination at $600^{\circ} \mathrm{C}$ in a muffle furnace. The sum of the amino acids analysed by the method of ninhydrin reaction, using an amino acid analyzer (Spackman et al., 1958), was established as the total protein content in the solid samples. In the effluents, the concentration of soluble protein (Lowry et al., 1951), total sugars (Dubois et al., 1956), amino acids and reducing sugars (Bernfeld, 1951) were also determined. All analytical determinations were made in duplicate. The composition of chitin effluents (squid peptones, SP) is summarized in Table 1 and Table S2 (supplementary material).

\subsection{Microbiological procedure}

Pediococcus acidilactici NRRL B-5627 was used in the evaluation of chitin effluents (squid peptones, SP) and Carnobacterium piscicola CECT 4020 
(Spanish Type Culture Collection) was the indicator microorganism for bacteriocin (Pediocin SA-1) bioassays. Stock cultures were stored at $-80^{\circ} \mathrm{C}$ on MRS medium with $25 \%$ glycerol. Inocula $(0.5 \%, v / v)$ consisted of cellular suspensions from $16 \mathrm{~h}$ aged in MRS, adjusted to an optical density-OD (700 $\mathrm{nm})$ of 0.900 .

\subsubsection{Culture media, sampling, analytical and modelling methods}

The composition of the culture media is shown in Table S3 (supplementary material). MRS commercial medium (Pronadisa, Spain) was used as control. In all cases, initial $\mathrm{pH}$ was adjusted to 7.0 with $5 \mathrm{M} \mathrm{NaOH}$ and solutions sterilised at $101^{\circ} \mathrm{C}$ for $1 \mathrm{~h}$. Micro-organisms were grown in $300 \mathrm{~mL}$ Erlenmeyer flasks with $180 \mathrm{~mL}$ of medium at $30^{\circ} \mathrm{C}$ and orbital agitation of $200 \mathrm{rpm}$. Cultures were carried out in duplicate. At pre-established times, each culture sample was divided into two aliquots.

The first aliquot was centrifuged at $4750 \mathrm{~g}$ for $20 \mathrm{~min}$ and the sediment resuspended in distilled water to an adequate dilution for measuring OD at 700 $\mathrm{nm}$. This OD was transformed in dry weight (biomass in $\mathrm{g} / \mathrm{L}$ ) using a calibration curve. The supernatant was used for the measurement of reducing sugars (Bernfeld, 1951), soluble protein (Lowry et al., 1951), lactic and acetic acids. These organic acids were quantified by HPLC analysis (refractive index detector), using an ION-300 column (Transgenomic, USA) with 6 mM sulphuric acid as mobile phase (flow $=0.4 \mathrm{~mL} / \mathrm{min}$ ) at $65^{\circ} \mathrm{C}$. Methods for the extraction and quantification of bacteriocins were previously described in detail (Cabo et 
al., 1999; Murado et al., 2002), using C. piscicola as indicator. All assays and analyses were carried out in duplicate.

The mathematical model employed to describe the kinetic profiles of $P$. acidilactici growth and metabolic production was the following logistic equation (Vázquez and Murado, 2008a):

$$
P=\frac{P_{m}}{1+\exp \left[2+\frac{4 v_{P}}{P_{m}}\left(\lambda_{P}-t\right)\right]}
$$

where, $P$ is the concentration of the corresponding bioproduction ( $X$ : biomass, La: lactic acid, $A$ : acetic acid or $B$ : bacteriocin) (in $\mathrm{g} / \mathrm{L}$ for $X, L a, A$; and $\mathrm{BU} / \mathrm{mL}$ for $B) ; t$ is the time of culture (h); $P_{m}$ is the maximum concentration of each bioproduction in the asymptotic phase $(\mathrm{g} / \mathrm{L}$ or $\mathrm{BU} / \mathrm{mL}) ; v_{P}$ is the maximum bioproduction rate $\left(\mathrm{g} \mathrm{L}^{-1} \mathrm{~h}^{-1}\right.$ or $\left.\mathrm{BU} \mathrm{mL}^{-1} \mathrm{~h}^{-1}\right)$; and $\lambda_{P}$ is the lag phase of the bioproductions (h).

\subsection{Degree of deacetylation of chitosan}

The degree of deacetylation (DD) of chitosan samples was determined by ${ }^{1} \mathrm{H}$ NMR using a $400 \mathrm{MHz}$ Bruker Avance II system. Spectra were recorded for solutions of chitosan in $0.056 \mathrm{M} d-$ TFA in $\mathrm{D}_{2} \mathrm{O}$ with a concentration of $7 \mathrm{~g} / \mathrm{L}$. Chemical shifts are expressed in ppm (residual HOD solvent signal as reference). Mestrenova 10.0 software (Mestrelab Research) was used to process the spectra. DD values were calculated from the relationship between acetyl integrals (N-acetyl: $\mathrm{NAc}$ and $\mathrm{AcOH}$ ) and the integral sum of $\mathrm{H} 2-\mathrm{H} 6$ 
protons (glucosamine: GluN and N-acetylglucosamine: GluNAc) (FernandezMegia et al., 2005; Novoa-Carballal et al., 2010).

\subsection{Molecular weight of chitosan}

Molecular weight of chitosan samples was estimated after Gel Permeation Chromatography (GPC) with triple detection: refractometer, right angle light scattering $(670 \mathrm{~nm})$ and viscometer. Chitosan was dissolved at a concentration of $1 \mathrm{~g} / \mathrm{L}$ in $0.15 \mathrm{M}$ ammonium acetate and $0.2 \mathrm{M}$ acetic acid at $\mathrm{pH} 4.5$ (GPC buffer). Separation was achieved on a Malvern Viscotek TDA 305 system with a set of four columns: Novema Precolumn $(10 \mathrm{~mm}, 8 \times 50 \mathrm{~mm})$, Novema $30 \AA$ $(10 \mathrm{~mm}, 8 \times 300 \mathrm{~mm})$, Novema $1000 \AA(10 \mathrm{~mm}, 8 \times 300 \mathrm{~mm})$ and Novema 1000 $\AA(10 \mathrm{~mm}, 8 \times 300 \mathrm{~mm})$ from Polymer Standards Service, Mainz, Germany. Samples were eluted in the GPC buffer at $1 \mathrm{~mL} / \mathrm{min}$ and $30^{\circ} \mathrm{C}$. The detectors were calibrated with a narrow standard of pullulan of $47 \mathrm{kDa}$ and polydispersity index 1.07 (Polymer Standards Service, Mainz, Germany). A refractive index increment value $(\mathrm{dn} / \mathrm{dc})$ of 0.18 was used to calculate absolute molecular weight of all chitosan samples (Sorlier et al., 2003).

\subsection{Valorisation of chitosan effluents}

Alkaline effluents from chitosan production can be sustainably recovered for application in other chemical and biotechnological processes. Initially, an enzymatic hydrolysate of shark cartilage using Alcalase was prepared following the procedure described by Vázquez et al. (Vázquez et al., 2016). Subsequently, the hydrolysate was separated into four aliquots to continue with the next step of purification: precipitation/redissolution in an alkaline-alcoholic- 
saline (AAS) medium. To this end, three aliquots were processed with alkaline effluents generated in the deacetylation of chitin, each effluent derived from the proteolysis of $L$. opalescens pens following either chemical or enzymatic (Alcalase and Esperase) methods. The effluents were previously diluted up to a concentration of $0.54 \mathrm{M} \mathrm{NaOH}$. The fourth aliquot served as control and was treated with a fresh solution of $0.54 \mathrm{M} \mathrm{NaOH}$. In all cases, $1.17 \mathrm{~V}$ of $\mathrm{EtOH}$ along with $2.5 \mathrm{~g} / \mathrm{L}$ of $\mathrm{NaCl}$ were added for glycosaminoglycan precipitation. Finally, neutralized aqueous solutions of chondroitin sulphate (CS) were purified by means of an ultrafiltration (UF) system equipped with 100 and $30 \mathrm{kDa}$ cut-off membranes (Blanco et al., 2015). UF equipment was configured to work under total recirculation assembly. Four diavolumes of distilled water were passed through the UF membranes (diafiltration operatory, DF) to enhance the purity of CS.

\subsection{Numerical and statistical analyses}

Data fitting procedures and parametric estimations were carried out by minimisation of the sum of quadratic differences between observed and modelpredicted values, using the non-linear least-squares (quasi-Newton) method provided by the macro 'Solver' of the Microsoft Excel spreadsheet. Confidence intervals from the parametric estimates (Student's t test) and consistence of mathematical models (Fisher's F test) were evaluated by "SolverAid" macro.

\section{Results and Discussion}

L. opalescens squid pens represent the $1 \%$ of the total weight of whole squid (Joseph et al., 1987). The content of moisture, ash, protein and lipids (\% per dry 
solid) of $L$. opalescens pen was: $67.59 \pm 0.19 \%, 0.61 \pm 0.05 \%, 73.58 \pm 0.19 \%$ and $0.10 \pm 0.02 \%$, respectively. The remaining fraction until reaching $100 \%$ corresponds to chitin. The values obtained in this study are rather similar than those found for Illex argentinus: $74.61 \%$ of protein, $0.8 \%$ of ash and 0.2 of fat (Joseph et al., 1987) and $66.38 \%$ of protein, $0,28 \%$ of ash and $0.07 \%$ of lipids (Vázquez et al., 2017a).

\subsection{Optimal conditions for chitin production}

The kinetics of hydrolysis mediated by Alcalase and Esperase are depicted in Figure S2 (supplementary material). The corresponding calculated data of $H_{m}$ and experimental data of chitin present in solids and protein liberated to the effluents (Table S4, supplementary material) were modelled using second-order equations (Table 2). The purity of chitin recovered in the solid samples achieved maximum levels ranging $85-89 \%$. The outcomes of the multivariate analysis indicate that the statistical signification of coefficients was comparatively very similar in each one of the responses quantified and also between the two proteases employed. In all situations, the quadratic effects of temperature and $\mathrm{pH}$ were always statistically significant and of negative sign. Previous reports working with similar and other fishing by-products revealed similar experimental and theoretical behaviours (Blanco et al., 2015; Vázquez et al., 2017b; Vázquez et al., 2017c).

The values of the coefficients of determination adjusted were generally remarkable demonstrating a good correlation between experimental and theoretical data (Table 2). Figure 1 displays a representation of the predicted 
surfaces generated by the second order equations summarized in Table 2 for the different responses quantified as a function of the variables studied. Although the results from F-Fisher tests are not shown, both F1 and F2 ratios were in all cases satisfied and therefore the consistency of the polynomial equations was validated. Based on these equations the optimal conditions were calculated by numerical derivations (Table 2) and they ranged from 51.9 to $55.6^{\circ} \mathrm{C}$ and $\mathrm{pH} 8.58-9.09$ for Alcalase and from 52.1 to $59.1^{\circ} \mathrm{C}$ and $\mathrm{pH} 8.85-9.41$ for Esperase. The compromise values of the variables that maximize the production of chitin (average between responses) were thereby defined as $53.2^{\circ} \mathrm{C} / \mathrm{pH} 8.84$ and $54.7^{\circ} \mathrm{C} / \mathrm{pH} 9.16$ for Alcalase and Esperase, respectively. The best conditions for the alkaline hydrolysis were found at $27.5^{\circ} \mathrm{C}$ and $0.2 \mathrm{M}$ of $\mathrm{NaOH}$ (Table 2). Predicted values of chitin purity in the mentioned optimal conditions are also summarized in Table 2 and were fixed among $84-90 \%$. The yield of chitin recovered (as average) in relation to the initial pens was $37.0 \pm 4.1 \%(\mathrm{w} / \mathrm{w})$.

Reports about chitin extraction from squid pen are relatively scarce, and to the best of our knowledge, the present study is the first to extract chitin from $L$. opalescens species. Besides, the majority of those reports consider only deproteinization by alkaline hydrolysis and no optimization is carried out. At best, single-factor experiments are performed (Kyoung et al., 2013). As a consequence, temperature $\left(50-100{ }^{\circ} \mathrm{C}\right), \mathrm{NaOH}$ concentration $(0.3-2 \mathrm{M})$, time $(1 \mathrm{~h}$ to overnight) and hydrolysis cycles vary considerably (Chandumpai et al., 2004; Kurita et al., 1993; Lavall et al., 2007; Tolaimate et al., 2000), probably leading to conditions harsher than necessary. For instance, chitin is obtained here at 
yields of $37 \% \pm 4.1 \%$ after treatment with $0.2 \mathrm{M} \mathrm{NaOH}$ at $27.5^{\circ} \mathrm{C}$ for $6 \mathrm{~h}$. For similar yields, other works use $0.3 \mathrm{M} \mathrm{NaOH} / 65^{\circ} \mathrm{C} / 3 \mathrm{~h}(40 \%$ yield) and $4.36 \mathrm{M}$ $\mathrm{NaOH} / 85^{\circ} \mathrm{C} / 3 \mathrm{~h}\left(42 \%\right.$ yield) (Lavall et al., 2007 ) or $1 \mathrm{M} \mathrm{NaOH}$ at $50^{\circ} \mathrm{C}$ for $5 \mathrm{~h}$ (yield 36-37\%) (Chandumpai et al., 2004). The optimization process applied, previously developed for I. argentinus (Vázquez et al., 2017), allows to produce chitin in comparable yields under mild conditions. In terms of released protein, chemical treatment at optimal conditions removes a protein mass representing $40 \%$ of initial pen weight (Table 2). While up to $58 \%$ release has been reported (Kurita et al., 1993), this requires two alkaline treatments, the second one with $2 \mathrm{M} \mathrm{NaOH}$ at $100^{\circ} \mathrm{C}$ for $4 \mathrm{~h}$. These extreme conditions lie outside the milder experimental range proposed here $\left(25-75^{\circ} \mathrm{C} ; 0.2-1.74 \mathrm{M}\right)$, which were set in accordance with the sustainability principles that guide this study. On the whole, the proposed approach produces high purity chitin (90\%) in good yields with lower energetic costs. This is achieved in particular via reduction of temperature, therefore contributing to process sustainability.

Beyond the above mentioned study with I. argentinus, other works considering enzymatic hydrolysis of squid pen are limited to a recent report using Alcalase to extract chitin from Loligo vulgaris (Abdelmalek et al., 2017). The authors report $3 \%$ protein in the final solid on a dry weight basis. Assuming $80 \%$ water content, this corresponds to $15 \%$ of wet weight, which is comparable to $85 \%$ chitin purity reported here (Table 2).

\subsection{Valorisation of effluents from chitin production}


Figure 2 illustrates the bacterial kinetics on the media formulated with SP, obtained under the optimal conditions to produce chitin, and commercial MRS medium employed as control. We can observe an increase in growth, organic acids production and nutrient uptake in low-cost media in comparison with MRS cultures. The experimental data of biomass, pediocin, lactic and acetic acid production were perfectly modelled by logistic equation (3). The numerical estimations for the kinetic parameters as well as the yields of production are both compiled in Table 3. The equations proved to be consistent in all cases (Fisher's $F ; \alpha=0.05$ ), and all the parameters were statistically significant (Student's t-test; $\alpha=0.05$ ). On the other hand, the coefficients of determination were excellent (more than 0.994 ) for growth, lactic acid and pediocin and very good for acetic acid $\left(R^{2}>0.972\right)$.

The production of maximum biomass, lactic and acetic acids was similar in SP media but significantly higher than those achieved in MRS. Nevertheless, the maximum rates for all the bioproductions did not show significant differences between the culture media assayed $(p>0.05)$. In addition, lag phases were always found at the same times for each production and medium. On the other hand, the metabolic formation of pediocin was $25 \%$ higher in MRS than in media formulated with SP. In commercial broth, the yields of bacteriocin production regarding the consumption of nutrients were also superior whereas in the rest of the cases SP media were the most effective. $P$. acidilactici was chosen due to it is a lactic acid bacteria producer of a potent bacteriocin (pediocin SA-1) (Anastasiadou et al., 2008). It is well known that lactic acid bacteria, especially for the production of bacteriocins, are demanding micro- 
organisms from the viewpoint of their nutritive requirements regarding protein source present in the culture media (Jensen and Hammer, 1993; Monnet and Gripon, 1994). Thus, as growth and metabolite production from $P$. acidilatici was satisfactory, it indicated that SP are an excellent substrate for microbial formulations. The capacity of SP as a source of protein (organic nitrogen) to support the growth of $P$. acidilactici and to produce lactic acid and pediocin was in concordance with previous studies employing marine peptones obtained from hydrolysates of shark and swordfish viscera (Vázquez et al., 2008) and wastewater from the industrial processing of octopus (Vázquez and Murado, 2008b).

From an economic point of view, the use of SP as ingredients represents significant savings compared to MRS: up to four-fold in the cost of biomass production (in $€ / g X$ ), three-fold for lactic acid ( $€ / g$ La) and two-fold for pediocin production (€/BU B).

\subsection{Production and characterisation of chitosan}

The deacetylation process of the chitin generated under the optimal conditions described in section 3.1. was investigated following the experimental plan defined in Table S1 (supplementary material). As an example, Figure S3 (supplementary material) shows the NMR spectrum of a chitosan sample (used to calculate deacetylation degree) along with a GPC eluogram for molecular weight determination. The theoretical 3D-surfaces predicted by the fitting of the experimental data to the second order models, as represented by schematic equation (1), are shown in Figure 3. These forms (convex dome) are identical 
regardless of the origin of the chitin samples, either obtained by chemical or enzymatic proteolysis. Table 4 summarizes the complete results of the polynomial equations that simulate the response surfaces defined. In the three cases, the effect of the first order for time and alkali concentration was positive and the second order effect was always negative for both independent variables. Once again, the numerical derivation of equations from Table 4 led to the optima values of $15.9-16.2 \mathrm{~h}$ and $15.9-16.1 \mathrm{M}$ of $\mathrm{NaOH}$ to obtain chitosan with deacetylation degrees higher than $94 \%$. These tendencies and numerical outcomes were similar to those found for $I$. argentinus by-products (Vázquez et al., 2017a).

The molecular weights of the chitosan produced, expressed as number average molecular weight $(\mathrm{Mn})$ are displayed in Figure $3 . \mathrm{Mn}$ ranged from $111 \mathrm{kDa}$ (polydispersity index, PDI, 2.40) to $263 \mathrm{kDa}$ (PDI 1.63) for chitosan obtained from chemically deproteinized chitin; from $85 \mathrm{kDa}$ (PDI 1.60) to $215 \mathrm{kDa}$ (PDI 1.41) for the enzymatic process with Alcalase; and from $205 \mathrm{kDa}$ (PDI 1.27) to 316 kDa (PDI 1.81) for Esperase deproteinization. Chitin samples treated under mild conditions in the experimental design were not soluble in the GPC buffer and molecular weights of those samples could not be quantified.

The apparent higher molecular weight of chitosan obtained from chitin treated with Esperase is confirmed by comparing the Mn values of the five replicates processed at the centre of the experimental domain $(12.5 \mathrm{~h}, 12.5 \mathrm{M} \mathrm{NaOH})$. Mean Mn values and corresponding standard deviations (STD) are 229 \pm 25 , $182 \pm 23$ and $301 \pm 19 \mathrm{kDa}$ for chemical, Alcalase and Esperase deproteinizations 
respectively (associated PDIs of $1.90 \pm 0.51,1.70 \pm 0.28$ and $1.86 \pm 0.19$ respectively). Deacetylation degrees were not substantially different for either method, with mean DD values ranging from 88 to $89 \%( \pm 1 \%)$.

Strict comparison of molecular weights with other reports is not possible, since, as already pointed out, this is the first study on chitin and chitosan production from L. opalecens. It is however possible to compare with chitosan obtained from $I$. argentinus using the same methodology (Vázquez et al., 2017a). Mn results are quite similar, with reported $M n$ of $262 \pm 32,187 \pm 17$ and $253 \pm 19$ for chemical, Alcalase and Esperase deproteinizations respectively. This is in contrast with the large differences found in molecular weight of chitosan, as high as 9-10 MDa in Loligo lessoniana and Loligo formosana (Chandumpai et al., 2004), 8.5 MDa in Loligo chenisis (Cuong et al., 2016), 320-595 kDa in L. vulgaris (Tolaimate et al., 2000), 238-246 kDa in Sepipotheutis lessoniana and as low as $145 \mathrm{kDa}$ in Loligo forbessii (Subhapradha et al., 2013). In light of the similarities in molecular weight when estimated using the same methods, it can be argued that methodological bias are behind these large differences rather than inter-species variability.

3.4. Alkaline effluents from chitosan production for chondroitin sulfate fractionation.

One of the most important and high added-value biocompounds that can be recovered from marine and fishing wastes are glycosaminoglycans, mainly CS. This polysaccharide present in cartilaginous tissues from chondrichthyan fish is a biopolymer of wide and fundamental importance in nutraceutical and tissue 
engineering formulations directed to the regeneration of cartilage and proliferation of chondrocytes (Silva et al., 2013; Soares da Costa et al., 2017). The procedures for its isolation from marine sources include sequential steps of enzymatic proteolysis followed by selective precipitation/redissolution using AAS solution and final purification by UF/DF (Blanco et al., 2015).

Thereby in the process of precipitation/redissolution, the alkali needed for the AAS medium could be provided by chitosan effluents. These wastewaters (in this assay those obtained in the center of the experimental domain) were diluted from a $\mathrm{NaOH}$ concentration of $12.5 \mathrm{M}$ (also containing protein impurities and acetyl groups cleaved from chitin) to $0.54 \mathrm{M}$, the optimum reported level for processing head cartilage of blue shark (Vázquez et al., 2016). Table 5 shows results of purity of the CS recovered using chitosan effluents against the control solution. In the first precipitation and redissolution step, CS purities were similar (74-75\%) among alkaline effluents $(p>0.05)$, but significantly inferior when compared with almost $84 \%$ purity of the fresh $\mathrm{NaOH}$ control solution $(p<0.05)$. The subsequent step of membrane purification enhanced the purity of all CS samples similarly, therefore maintaining the differences between tested wastewaters and control. CS obtained with $\mathrm{NaOH}$ reached $99 \%$ purity, which is required for applications in biomedicine and regenerative medicine devices (e.g., scaffolds). While the lower purity of the CS produced with chitosan effluents, almost $90 \%$, is not sufficient in these fields, it is certainly suitable for other applications such as an ingredient in nutraceutical formulations.

\subsection{Sustainability of valorisation processing of squid pen by-products}


To the best of our knowledge, this is the first report in which wastewaters generated on the chitosan processing have been recycled for their use as substrate in another biotechnological production. Similarly, the works studying the potential ways for chitin effluents management and useful application are basically unexplored in literature.

In Figure 4, a flowchart describing the mass balance of the bioproductions developed in the present study is represented. Based on such data, we will define the base case of the production of chitin/chitosan from $1 \mathrm{~kg}$ of dried pens without valorisation of effluents of the enzymatic hydrolysis and from the deacetylation process. We represent the mass flows across the different steps in the process (based on mass conservation balance) by the scheme in Figure 5 and the Sankey diagram in Figure 6, where the widths of the bands are directly proportional to these flows. We can state that most of the outputs to the environment (almost 96\%) are liquid effluents (up to $17 \mathrm{~L}$ of liquid waste are generated to process $1 \mathrm{~kg}$ of dried pens from the enzymatic hydrolysis $(63.58 \%$ of the total) with high content of organic matter and from the alkaline treatment (36.42 \% of effluents). Both streams have to be properly treated or managed to avoid negative environmental impacts.

To overcome this issue, for productions scaled to real industrial level, we propose an integral solution for valorising these effluents from the different steps in the chitin extraction processes from $L$. opalescens pens as potential raw materials for microbial bioconversion of squid peptones for bacterial growth along with the utilisation of alkaline effluents to obtain chondroitin sulphate for 
nutraceutical use. This strategy takes advantage of the integration of already existing, well-defined valorisation processes towards a maximization of the economic profit along with a minimization of environmental costs under the ideas of marine biorefinery and circular economy (Antelo et al., 2015).

Therefore, as depicted in Figures 6 and 7, we consider the part of the effluent from the enzymatic hydrolysis (with high organic matter) as a new input to the culture of micro-organisms and the remaining alkaline effluent as an input to $90 \%$ CS production. The resulting mass flows across this new configuration are represented in Figure 8. With this mass integration we achieve a zero effluent emission scenario for the base case of chitin/chitosan production, since all the liquid flows out to the environment are reintroduced in other processes, closing the resources reutilization cycle, while minimising the impacts associated to fresh resource consumption in the bioconversion and $90 \%$ CS processes. In addition, the economic benefits of the integrated scenario represented in Figure 7 are a $6.6 \%$ higher than the base case without effluent valorisation, considering these benefits as: Profit $=$ Product sales - Input mass flows costs Effluents management.

This fact shows that the earnings obtained by the increased amounts of products resulting from the proposed mass integration of effluents from different steps of the chitin/chitosan production into existing value chains for obtaining 90\% CS and bioconversions are higher that the costs of raw materials and the additional management required to properly deal with the higher levels of liquid effluents obtained. 
Regarding environmental considerations of this integrated scenario, it can be stated in the Sankey diagram in Figure 8 that the $90 \%$ CS obtaining process is highly demanding on water and $\mathrm{EtOH}$ inputs that results in a high level of liquid alcoholic effluents that must be properly managed. Despite the fact that it is not an objective of this work to analyse how to handle these output streams (since the aim is to analyse the chitin/chitosan process), it can be briefly mentioned that, for instance, liquid effluents from the $90 \%$ CS process, once purified by UF/DF operations, can be reintroduced in the extraction processes in those steps where water supply is required. Additionally, a rectification procedure to regenerate $\mathrm{EtOH}$ can be considered, importantly diminishing the fresh raw material requirements of this process. Finally, the liquid effluent from bacterial culture can be reutilised again for this purpose once lactic and acetic components have been removed by electrodialysis (Othman et al., 2017) (to avoid substrate inhibition) due to the remaining content on sugars not consumed in the first fermentation.

From all exposed, it can be concluded that our valorising strategy is attractive since the proposed higher integration of mass flows in bio-based processes can be considered as a strong contribution to the global bio-economy.

\section{Conclusions}

In this work we applied sustainability principles to the treatment of one the main sources of waste in the squid processing industry, i.e. the squid pen. As a result, we propose an integral process built around the isolation of chitin and its conversion to chitosan, valuable materials with wide applicability. We 
established optimal conditions for both processes, producing high quality materials with decreased energetic consumption. We demonstrated, by means of MFA approach, the integral aspect of our proposal by also recycling waste streams of the main valorisation process towards a zero effluent scenario for the chitin/chitosan production. First, the potential of protein-rich effluents from pen deproteinization as nitrogen source for culture media was proven with a fastidious microorganism, $P$. acidilactici. Second, alkaline effluents from chitosan conversion were turned into inputs for another valorisation process, producing chondroitin sulfate from shark heads with applicability in the nutraceutical industry. This integrated scenario represents an increase on economic profit of up to $7 \%$ compared to the chitin/chitosan production base case, while minimising environmental impacts related to the use of fresh resources and generation of liquid effluents.

\section{Conflicts of Interest}

The authors declare no conflict of interest.

\section{Acnowledgements}

The authors thank to Ana Durán, Margarita Nogueira, Araceli Menduíña and Javier Fraguas for their excellent technical assistance. This research was funded by the projects IBEROS (0245_IBEROS_1_E, POCTEP 2015), CVMar+I (0302_CVMAR_I_1_P, POCTEP 2015) and BLUEHUMAN (EAPA_151/2016, UE-INTERREG Atlantic Area Programme). RNC thanks the Portuguese Foundation for Science and Technology (IF/00373/2014). 


\section{References}

Abdelmalek, B.E., Sila, A., Haddar, A., Bougatef, A., Ayadi, M.A., 2017. $\beta$-Chitin and chitosan from squid gladius: Biological activities of chitosan and its application as clarifying agent for apple juice. Int. J. Biol. Macromol. 104, 953962.

Adler-Nissen, J., 1986. Enzymic hydrolysis of food proteins. Elsevier Applied Science Publishers.

Anastasiadou, S., Papagianni, M., Filiousis, G., Ambrosiadis, I., Koidis, P., 2008. Pediocin SA-1, an antimicrobial peptide from Pediococcus acidilactici NRRL B5627: Production conditions, purification and characterization. Biores. Technol. 99 (13), 5384-5390.

Antelo, L.T., de Hijas-Liste, G.M., Franco-Uría, A., Alonso, A.A., Pérez-Martín, R.I., 2015. Optimisation of processing routes for a marine biorefinery. J. Cleaner Prod. 104, 489-501.

AOAC, 1997. Association of Official Analytical Chemistry. Methods of Analysis., 15th ed., Washington DC, USA.

Aranaz, I., Acosta, N., Civera, C., Elorza, B., Mingo, J., Castro, C., Gandía, M., Heras Caballero, A., 2018. Cosmetics and Cosmeceutical Applications of Chitin, Chitosan and Their Derivatives. Polym. 10 (2), 213.

Arvanitoyannis, I.S., Kassaveti, A., 2008. Fish industry waste: treatments, environmental impacts, current and potential uses. Int. J. Food Sci. Technol. 43 (4), 726-745.

Bernfeld, P., 1951. Enzymes of starch degradation and synthesis. Adv. Enzymol. 12, 379-427.

Blanco, M., Fraguas, J., Sotelo, C.G., Pérez-Martín, R.I., Vázquez, J.A., 2015. Production of chondroitin sulphate from head, skeleton and fins of Scyliorhinus canicula by-products by combination of enzymatic, chemical precipitation and ultrafiltration methodologies. Marine Drugs 13 (6), 3287-3308.

Bligh, E.G., Dyer, W.J., 1959. A rapid method of total lipid extraction and purification. Can. J. Biochem. Physiol. 37 (8), 911-917.

Box, G.E., Hunter, J.S., Hunter, W.G., 2005. Statistics for experimenters: design, innovation, and discovery. Wiley-Interscience New York.

Brunner, P.H., Rechberger, H., 2004. Practical handbook of material flow analysis. Int. J. Life Cycle Assess. 9 (5), 337-338.

Cabo, M., Murado, M., González, M.P., Pastoriza, L., 1999. A method for bacteriocin quantification. J. Appl. Microbiol. 87 (6), 907-914. 
Cuong, H.N., Minh, N.C., Van Hoa, N., Trung, T.S., 2016. Preparation and characterization of high purity $\beta$-chitin from squid pens (Loligo chenisis). Int. J. Biol. Macromol. 93, Part A, 442-447.

Chandumpai, A., Singhpibulporn, N., Faroongsarng, D., Sornprasit, P., 2004. Preparation and physico-chemical characterization of chitin and chitosan from the pens of the squid species, Loligo lessoniana and Loligo formosana. Carboh. Polym. 58 (4), 467-474.

Chaussard, G., Domard, A., 2004. New Aspects of the Extraction of Chitin from Squid Pens. Biomacromol. 5 (2), 559-564.

Cortizo, M. S., Berghoff, C. F., Alessandrini, J. L., 2008. Characterization of chitin from Illex argentinus squid pen. Carboh. Polym, 74(1), 10-15.

Domard, A., 2011. A perspective on 30 years research on chitin and chitosan. Carboh. Polym. 84 (2), 696-703.

Dubois, M., Gilles, K.A., Hamilton, J.K., Rebers, P.A., Smith, F., 1956. Colorimetric method for determination of sugars and related substances. Anal. Chem. 28, 350-356.

FAO, 2011. Review of the state of world marine fishery resources. http://www.fao.org/docrep/015/i2389e/i2389e.pdf

FAO, 2016. Fishery statistical collection.

http://www.fao.org/fishery/statistics/global-capture-production/en

Fernandez-Megia, E., Novoa-Carballal, R., Quiñoá, E., Riguera, R., 2005. Optimal routine conditions for the determination of the degree of acetylation of chitosan by $1 \mathrm{H}-\mathrm{NMR}$. Carboh. Polym. 61(2), 155-161.

Hamed, I., Özogul, F., Regenstein, J.M., 2016. Industrial applications of crustacean by-products (chitin, chitosan, and chitooligosaccharides): A review. Trends Food Sci. Technol. 48, 40-50.

Jensen, P.R., Hammer, K., 1993. Minimal requirements for exponential growth of Lactococcus lactis. Appl. Environ. Microbiol. 59 (12), 4363-4366.

Joseph, J., Prabhu, P., Madhavan, P., 1987. Utilisation of squid waste as meal. Fish. Technol. 24 (1), 41-43.

Kurita, K., Tomita, K., Tada, T., Ishii, S., Nishimura, S.I., Shimoda, K., 1993. Squid chitin as a potential alternative chitin source: deacetylation behavior and characteristic properties. J. Polym. Sci. Part A: Polym. Chem. 31 (2), 485-491.

Kyoung, Y.D., Kyoon, N.H., Witoon, P., 2013. Preparation and characteristics of squid pen $\beta$-chitin prepared under optimal deproteinisation and demineralisation condition. International Journal of Food Science \& Technology 48(3), 571-577. 
Lavall, R.L., Assis, O.B.G., Campana-Filho, S.P., 2007. $\beta$-Chitin from the pens of Loligo sp.: Extraction and characterization. Biores. Technol. 98 (13), 24652472.

Lowry, O.H., Rosebrough, N.J., Farr, A.L., Randall, R.J., 1951. Protein measurement with the Folin phenol reagent. J Biol. Chem. 193 (1), 265-275.

Monnet, V., Gripon, J., 1994. Métabolisme azoté des bactéries lactiques. Bacteries lactiques 1, 331-347.

Murado, M., González, M.P., Vázquez, J., 2002. Dose-response relationships: an overview, a generative model and its application to the verification of descriptive models. Enz. Microb. Technol. 31 (4), 439-455.

Novoa-Carballal, R., Fernandez-Megia, E., Riguera, R., 2010. Dynamics of Chitosan by $1 \mathrm{H}$ NMR Relaxation. Biomacromol. 11 (8), 2079-2086.

Othman, M., Ariff, A.B., Rios-Solis, L., Halim, M., 2017. Extractive Fermentation of Lactic Acid in Lactic Acid Bacteria Cultivation: A Review. Front. Microbiol. 8, 2285.

Patrizia Jereb, C.F.E.R., 2010. Cephalopods of the world. An annotated and illustrated catalogue of cephalopod species known to date. Volume 2. Myopsid and Oegopsid Squids, 4, 205.

Silva, J.M., Georgi, N., Costa, R., Sher, P., Reis, R.L., Van Blitterswijk, C.A., Karperien, M., Mano, J.F., 2013. Nanostructured 3D constructs based on chitosan and chondroitin sulphate multilayers for cartilage tissue engineering. PLoS ONE 8(2), e55451.

Soares da Costa, D., Reis, R.L., Pashkuleva, I., 2017. Sulfation of Glycosaminoglycans and Its Implications in Human Health and Disorders. Ann. Rev. Biom. Eng. 19 (1), 1-26.

Sorlier, P., Rochas, C., Morfin, I., Viton, C., Domard, A., 2003. Light scattering studies of the solution properties of chitosans of varying degrees of acetylation. Biomacromol. 4 (4), 1034-1040.

Spackman, D., Stein, W., Moore, S., 1958. Chromatography of amino acids on sulphonated polystyrene resins. An improved system. Anal. Chem. 30, 11901205.

Subhapradha, N., Ramasamy, P., Shanmugam, V., Madeswaran, P., Srinivasan, A., Shanmugam, A., 2013. Physicochemical characterisation of $\beta-$ chitosan from Sepioteuthis lessoniana gladius. Food Chem. 141 (2), 907-913.

Tolaimate, A., Desbrières, J., Rhazi, M., Alagui, A., Vincendon, M., Vottero, P., 2000. On the influence of deacetylation process on the physicochemical characteristics of chitosan from squid chitin. Polym. 41 (7), 2463-2469. 
Vázquez, J., Docasal, S., Prieto, M., González, M.P., Murado, M., 2008. Growth and metabolic features of lactic acid bacteria in media with hydrolysed fish viscera. An approach to bio-silage of fishing by-products. Biores. Technol. 99 (14), 6246-6257.

Vázquez, J.A., Murado, M.A., 2008a. Mathematical tools for objective comparison of microbial cultures. Application to evaluation of 15 peptones for lactic acid bacteria production. Biochem. Eng. J. 39, 276-287.

Vázquez, J.A., Murado, M.A., 2008b. Enzymatic hydrolysates from food wastewater as a source of peptones for lactic acid bacteria productions. Enz. Microb. Technol. 43 (1), 66-72.

Vázquez, J., Rodríguez-Amado, I., Montemayor, M., Fraguas, J., González, M., Murado, M., 2013. Chondroitin sulfate, hyaluronic acid and chitin/chitosan production using marine waste sources: Characteristics, applications and ecofriendly processes: A review. Mar. Drugs 11 (3), 747.

Vázquez, J.A., Blanco, M., Fraguas, J., Pastrana, L., Pérez-Martín, R., 2016. Optimisation of the extraction and purification of chondroitin sulphate from head by-products of Prionace glauca by environmental friendly processes. Food Chem. 198, 28-35.

Vázquez, J.A., Noriega, D., Ramos, P., Valcarcel, J., Novoa-Carballal, R., Pastrana, L., Reis, R.L., Pérez-Martín, R.I., 2017a. Optimization of high purity chitin and chitosan production from Illex argentinus pens by a combination of enzymatic and chemical processes. Carboh. Polym. 174, 262-272.

Vázquez, J.A., Ramos, P., Mirón, J., Valcarcel, J., Sotelo, C.G., Pérez-Martín, R.I., 2017b. Production of Chitin from Penaeus vannamei By-Products to Pilot Plant Scale Using a Combination of Enzymatic and Chemical Processes and Subsequent Optimization of the Chemical Production of Chitosan by Response Surface Methodology. Mar. Drugs 15 (6), 180.

Vázquez, J.A., Blanco, M., Massa, A.E., Amado, I.R., Pérez-Martín, R.I., 2017c. Production of fish protein hydrolysates from Scyliorhinus canicula discards with antihypertensive and antioxidant activities by enzymatic hydrolysis and mathematical optimization using response surface methodology. Mar. Drugs 15 (10), 306.

Yang, R., Li, H., Huang, M., Yang, H., Li, A., 2016. A review on chitosan-based flocculants and their applications in water treatment. Water Res. 95, 59-89.

Younes, I., Rinaudo, M., 2015. Chitin and Chitosan Preparation from Marine Sources. Structure, Properties and Applications. Mar. Drugs 13 (3), 1133.

Zeidberg, L.D., Hamner, W.M., Nezlin, N.P., Henry, A., 2006. The fishery for California market squid (Loligo opalescens)(Cephalopoda: Myopsida), from 1981 through 2003. Fish. Bull. 104 (1), 46-59. 


\section{TABLE CAPTIONS}

Table 1. Composition of the effluents generated from chitin production using $L$. opalescens pen by-products. The error value is the confidence intervals for $n=2$ and $\alpha=0.05$.

Table 2. Polynomial equations modelling the simultaneous effect of temperature $(T)$ and $p H$ on enzyme hydrolysis, and temperature $(T)$ and alkali concentration $(\mathrm{NaOH})$ on chemical hydrolysis of $L$. opalescens pens for the different responses determined. Optimal values of the two variables $\left(T_{o p t}, p H_{o p t}\right)$ and $\left(T_{o p t}, \mathrm{NaOH}_{\text {opt }}\right)$ to achieve the maximum responses ( $\left.Y_{\max }\right)$ from the empirical equations are also summarized. The coefficients of determination adjusted $\left(R_{a d j}^{2}\right)$ are also shown.

Table 3. Kinetic parameters obtained from logistic equation (2) used to model the production of biomass $(X)$, pediocin $(B)$, lactic $(L a)$ and acetic $(A)$ acids by $P$. acidilactici in the media defined in Table S3 (supplementary material). Error values are the confidence intervals $(\alpha=0.05)$. $R^{2}=$ determination coefficients between experimental and predicted data. $p$-values are determined from FFisher test $(\alpha=0.05)$. Production yields $\left(Y_{P / R s}\right.$ and $\left.Y_{P / P r}\right)$ are also summarized. Rs: reducing sugars; Pr: soluble protein; BU: bacteriocin unit.

Table 4. Polynomial equations modelling the simultaneous effect of time $(t)$ and concentration of alkali $(\mathrm{NaOH})$ on the deacetylation degree of chitosan produced from chitin recovered from $L$. opalescens pen. Optimal values of the two variables $\left(t_{o p t}\right.$ and $\left.\mathrm{NaOH}_{\text {opt }}\right)$ to reach maximum deacetylation $\left(Y_{\max }\right)$ from the empirical equations are summarized. The coefficients of determination adjusted $\left(R_{a d j}^{2}\right)$ are also shown.

Table 5. Values of purity for chondroitin sulphate (CS) in relation to protein content of the samples after the steps of selective Precipitation/Redissolution (Prec/Red) and UF/DF purification using alkaline effluents from chitosan production or $\mathrm{NaOH}$ fresh solution as reagents. 


\section{FIGURE CAPTIONS}

Figure 1. 3D-response surfaces describing the theoretical joint effect of temperature and $\mathrm{pH}$ on enzymatic hydrolysis (using Alcalase and Esperase) as well as the effect of temperature and alkali concentration on chemical hydrolysis to recover chitin from $L$. opalescens endoskeleton by-products.

Figure 2. Cultivation kinetics of $P$. acidilactici on different media formulated with squid peptones (SP) obtained from effluents of chitin production from $L$. opalescens endoskeletons. $\mathrm{O}$ : SP Chemical, $\square$ : SP Alcalase, $\triangle$ : SP Esperase and ๑: MRS. Experimental data of biomass $(X)$, lactic acid (La), acetic acid (A) and pediocin (B) were fitted to the logistic equation [3]. Consumption of reducing sugars (Rs) and proteins $(\mathrm{Pr})$ are also shown. Error bars are the confidence intervals for $n=2$ and $\alpha=0.05$.

Figure 3. 3D-response surfaces describing the theoretical joint effect of deacetylation time and alkali concentration on the chitosan production from chitin generated in the optimal conditions described in Table 1. The molecular weights of final chitosans dissolved in the GPC buffer are also shown in the histograms. The error bars in the chitosan samples obtained at the center of experimental domain $(12.5 \mathrm{~h} / 12.5 \mathrm{M}$ of $\mathrm{NaOH})$ are the confidence intervals for $\mathrm{n}=5$ and $\alpha=0.05$.

Figure 4. Flowchart of mass balance for the different bioproductions obtained from $L$. opalescens pen processing and the corresponding effluents generated. Calculation was based on $1 \mathrm{~kg}$ of dried pen.

Figure 5. Mass flow scheme for the chitin/chitosan production from dried squid (L. opalescens) pens

Figure 6. Sankey diagram for the base case corresponding to the chitin/chitosan production process without effluent treatment.

Figure 7. Mass flow scheme for the chitin/chitosan production from dried squid (L. opalescens) pens.

Figure 8. Sankey diagram for the scenario corresponding to the chitin/chitosan production process with mass effluent integration on existing valorization processes (lactic acid bacterium and CS $90 \%$ productions). 
Figure 1.

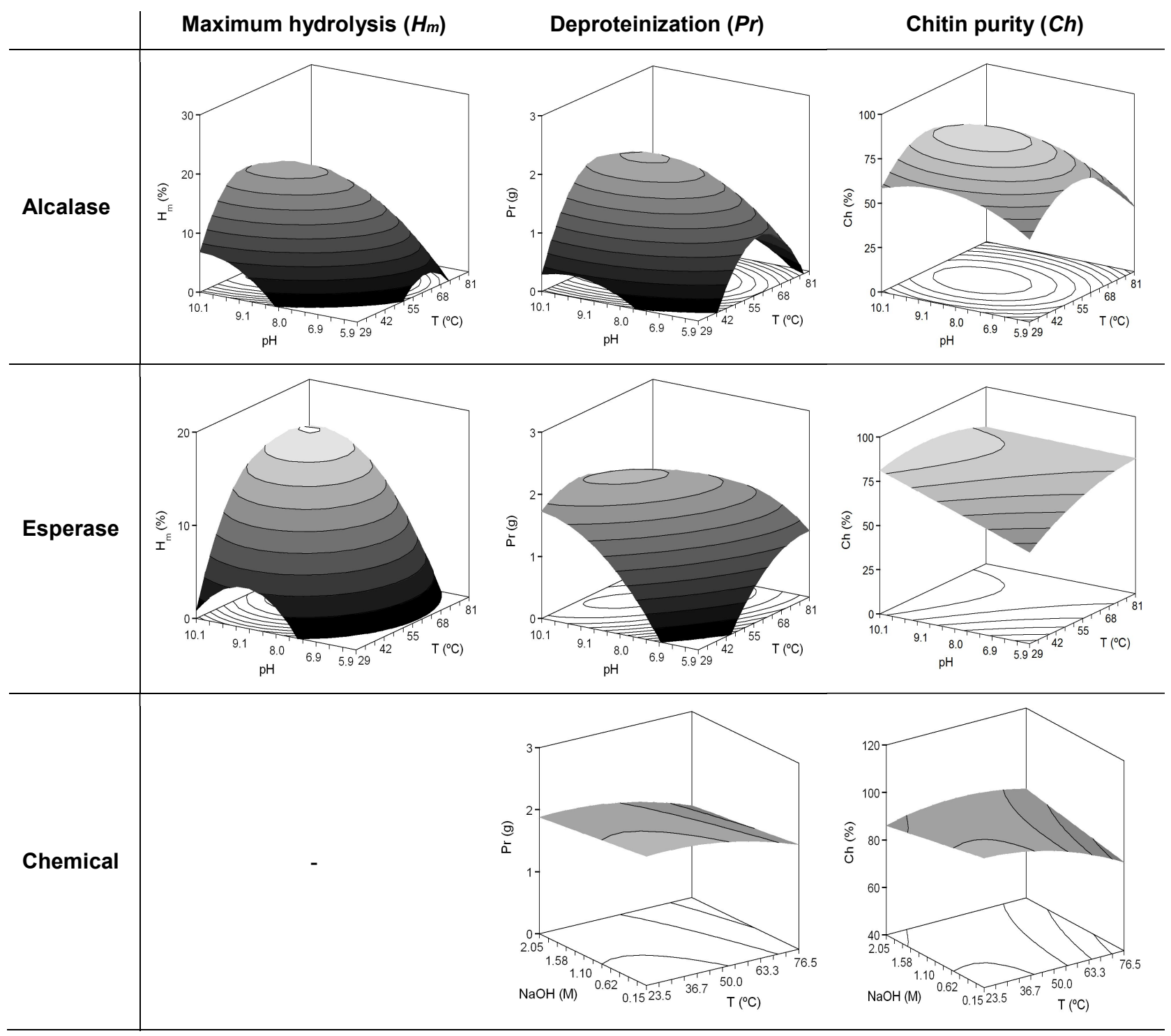


Figure 2.
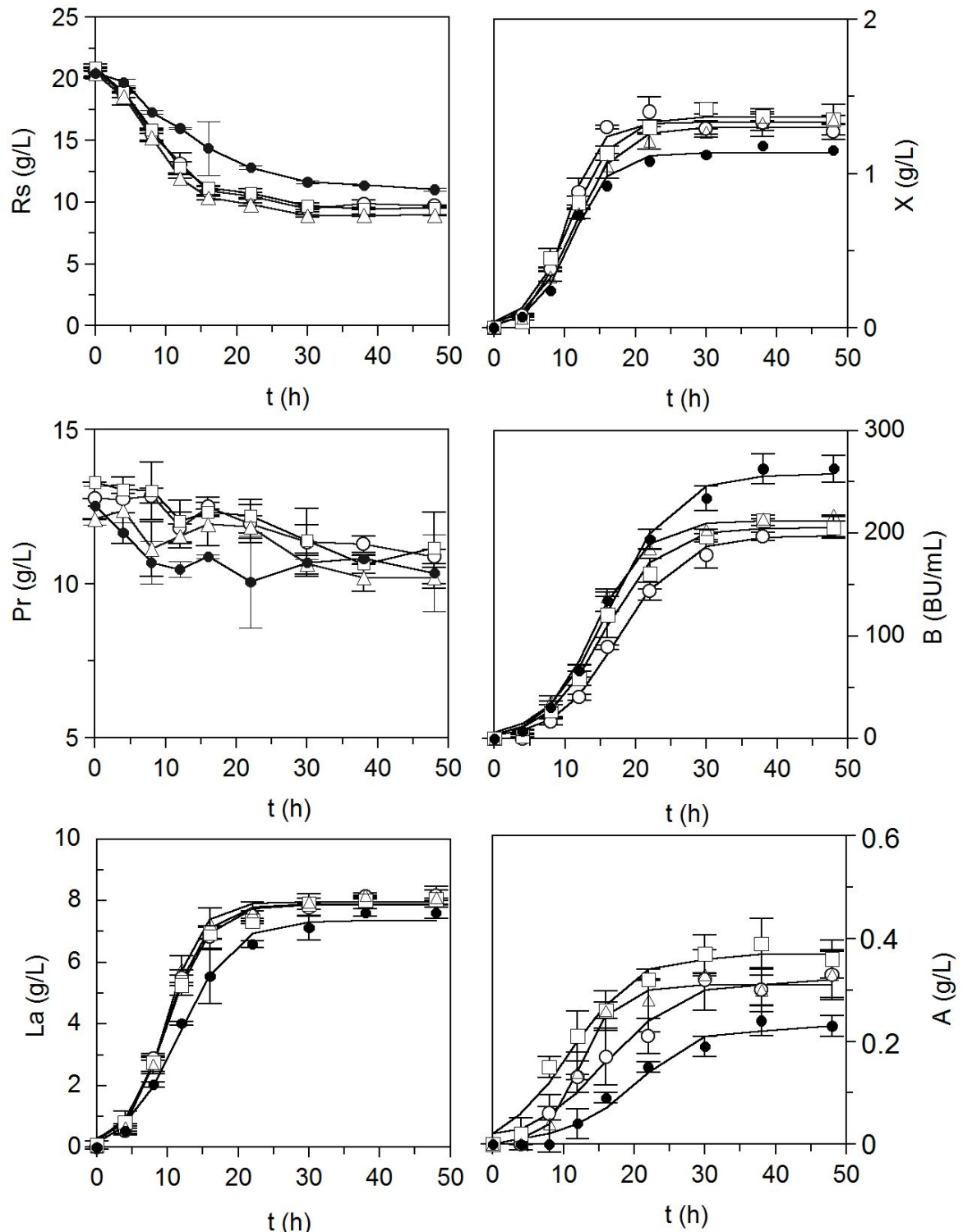
Figure 3.
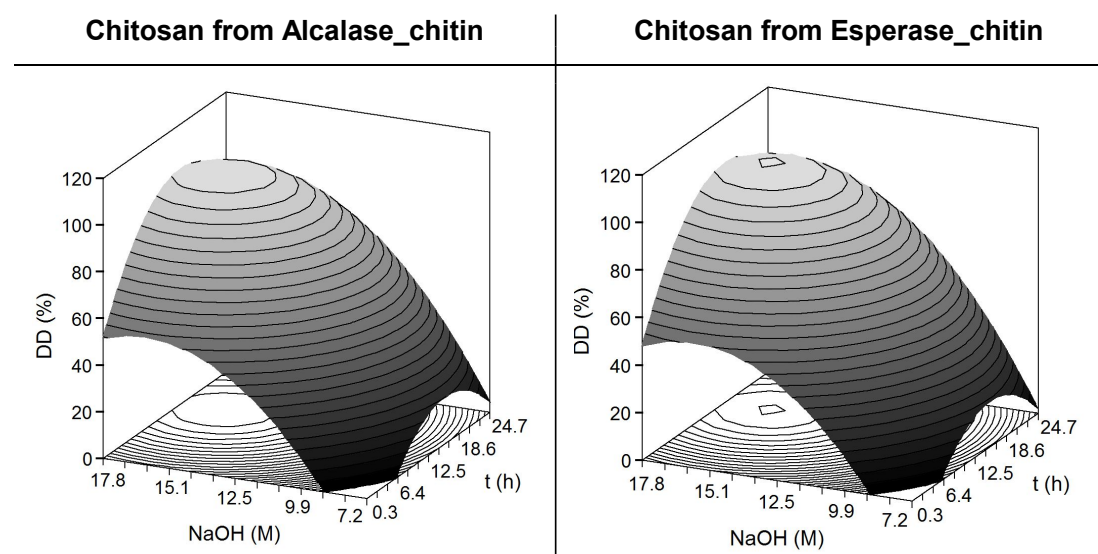

Chitosan from Chemical_chitin
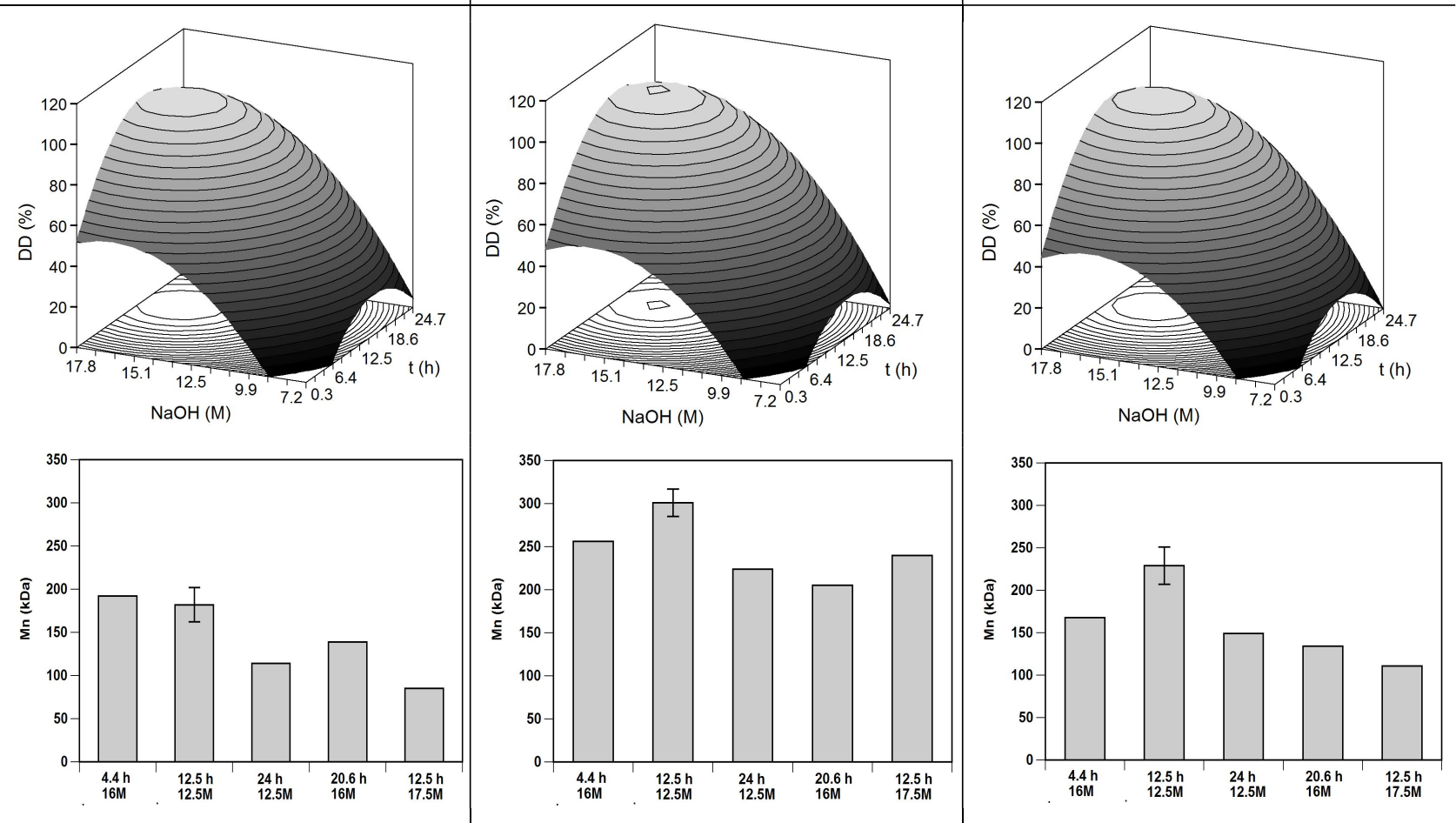
Figure 4.

fresh L. opalescens PEN (8.6 kg)

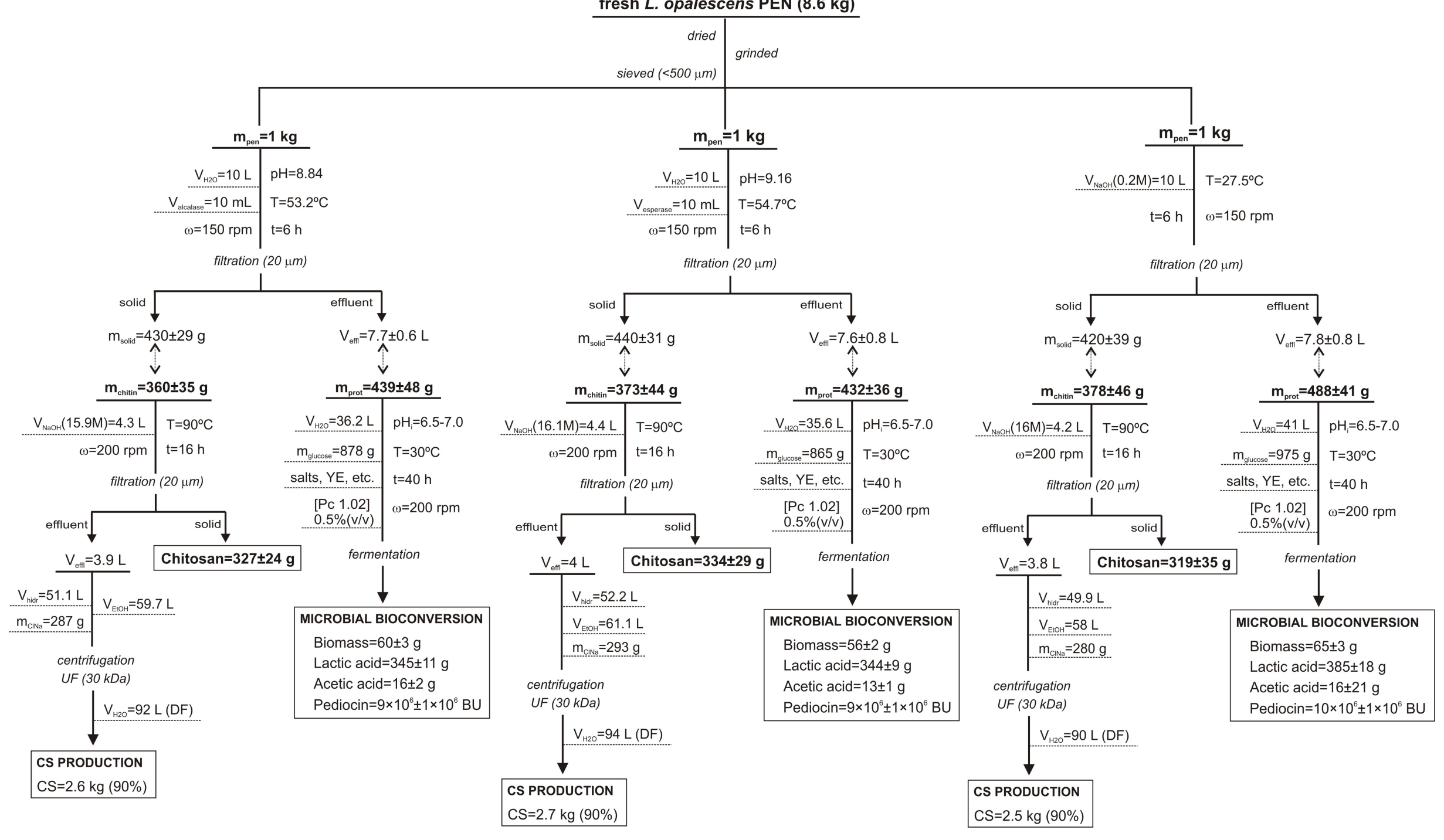


Figure 5.

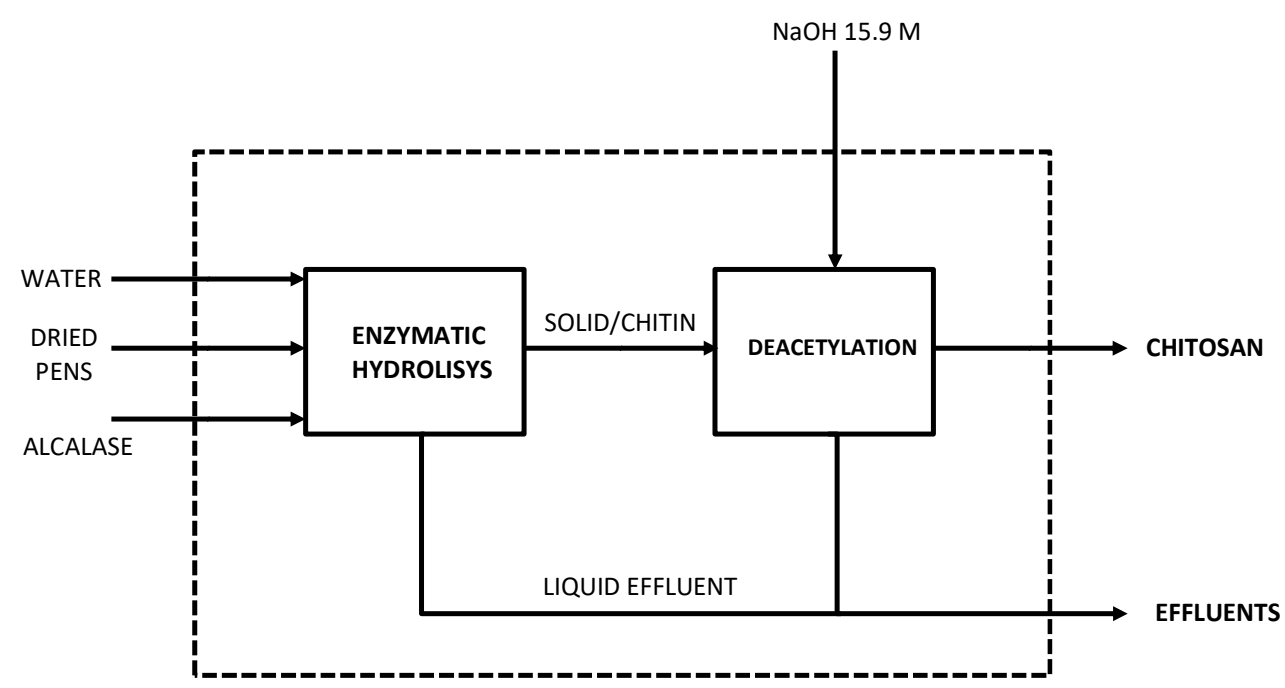


Figure 6.

Dried pens: 1,000

Hydrolysis: 11,010

Water: 14,300

$\mathrm{NaOH}$ Treatment: 9.764

Alcalase: 10

$\mathrm{NaOH}: 2,734$

Effluent: 17,317

CHITOSAN: 727 
Figure 7.

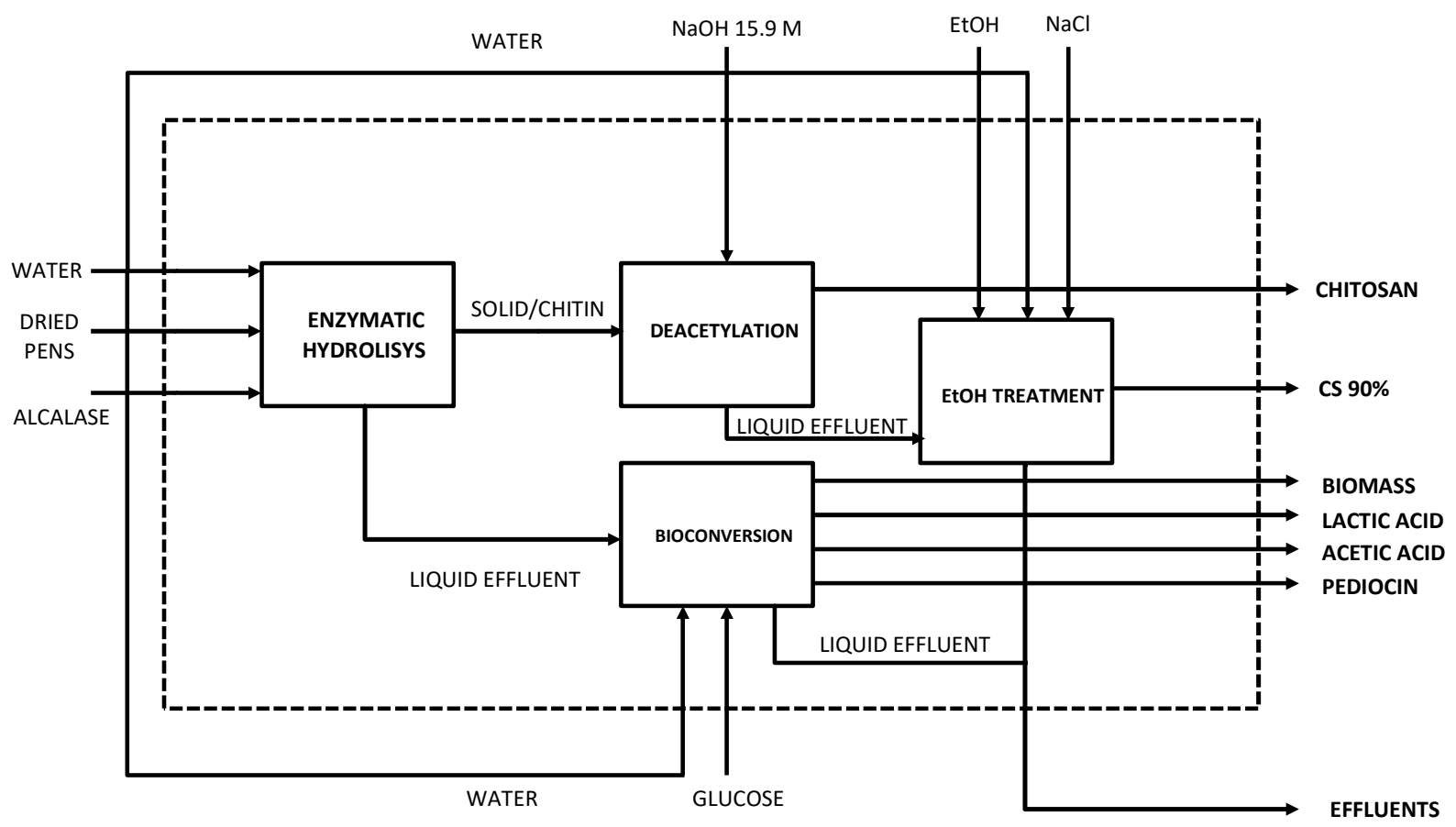


Figure 8.

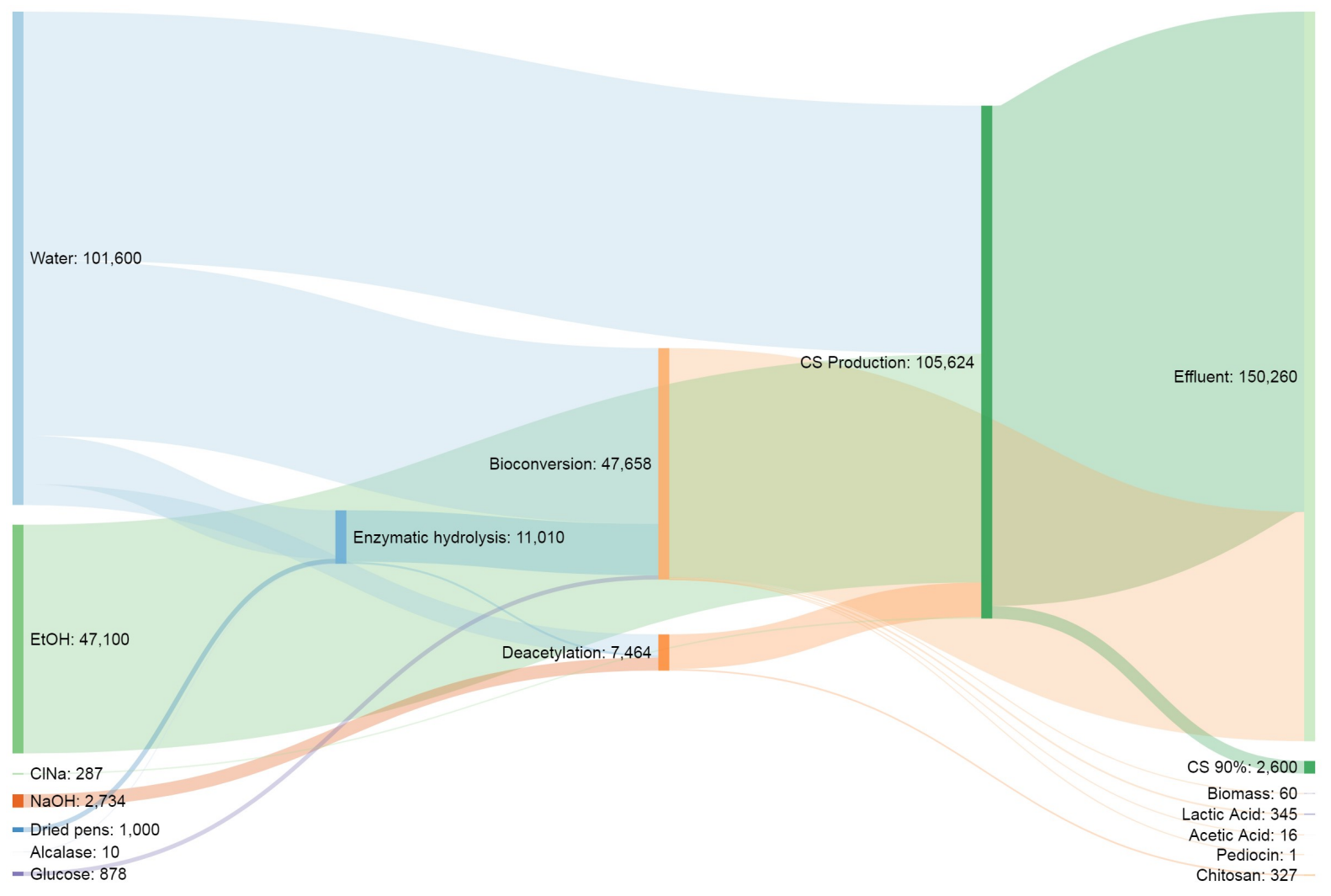




\section{Abbrevation list and symbiolic notations used.}

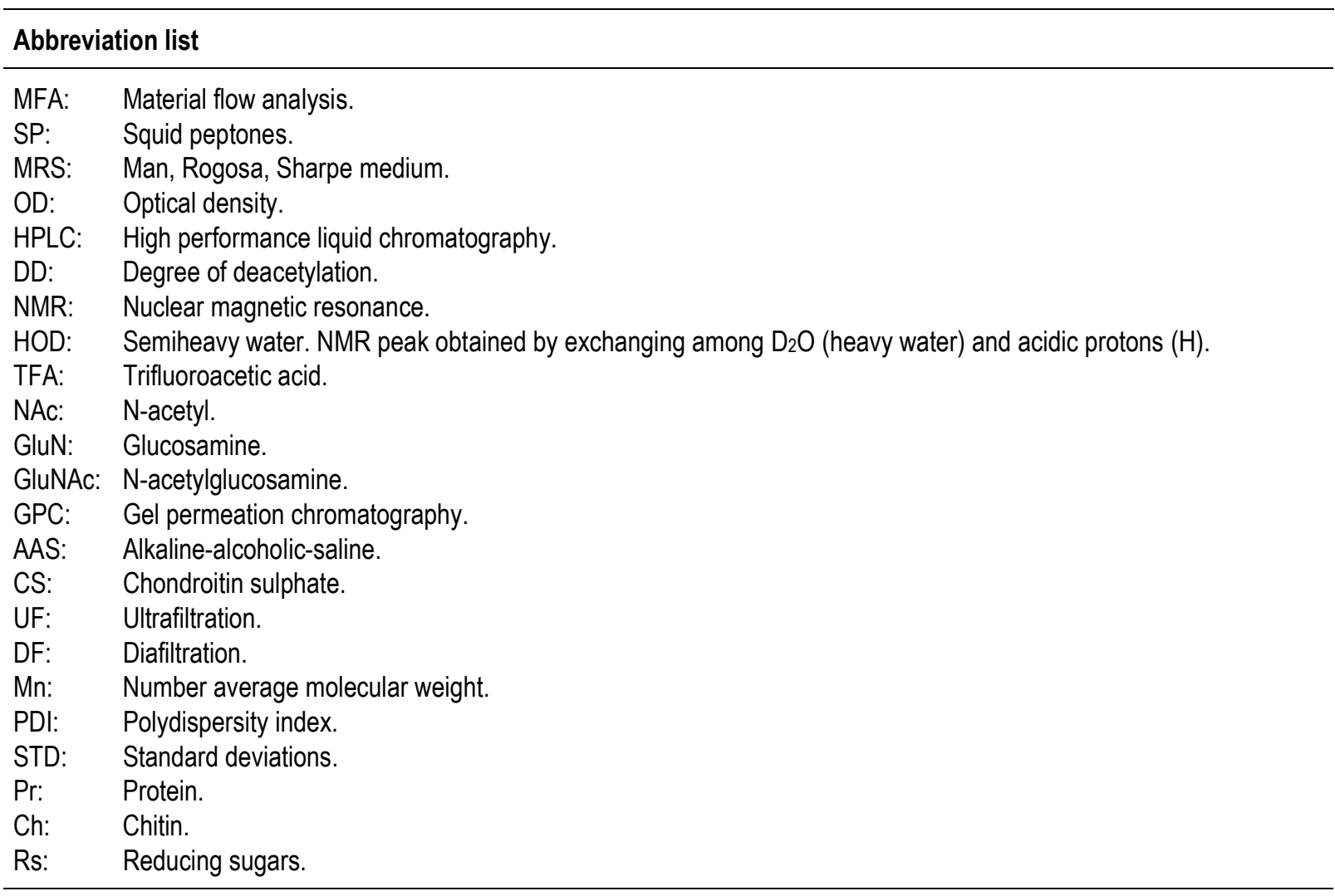

Symbolic notations used.

\section{Second order factorial design}

$Y$ : $\quad$ Response evaluated (dependent variable).

$b_{0}$ : Constant coefficient.

$b_{i}$ : Coefficient of linear effect.

$b_{i j}$ : Coefficient of combined effect.

$b_{i i}$ : Coefficient of quadratic effect.

$n$ : $\quad$ Number of variables.

$X_{i}: \quad$ Independent variable.

$X_{j}: \quad$ Independent variable.

\section{Weibull equation}

$H$ : $\quad$ Degree of hydrolysis. Unit: \%.

$t: \quad$ Time of hydrolysis. Unit: min.

$H_{m}$ : Maximum degree of hydrolysis. Unit: \%.

$\beta$ : $\quad$ Parameter related with the maximum slope of muscle hydrolysis (without unit).

$\tau$ : $\quad$ Time required to achieve the semi-maximum degree of hydrolysis. Unit: min.

\section{Logistic equation. BU: Bacteriocin arbitrary units.}

$P$ : $\quad$ Bioproductions ( $X$ : biomass, La: lactic acid, $A$ : acetic acid or $B$ : bacteriocin). Units: $g / L$ for $X, L a, A$; and $B U / m L$ for $B$.

$t: \quad$ Time of culture. Unit: $h$.

$P_{m}$ : Maximum concentration of each bioproduction in the asymptotic phase. Units: $\mathrm{g} / \mathrm{L}$ or $\mathrm{BU} / \mathrm{mL}$.

$V_{P}: \quad$ Maximum bioproduction rate. Units: $\mathrm{g} \mathrm{L}^{-1} \mathrm{~h}^{-1}$ or BU $\mathrm{mL}^{-1} \mathrm{~h}^{-1}$.

$\lambda_{P}: \quad$ Lag phase of the bioproductions. Unit: $h$

$Y_{P / R s}$ : Yield factor for bioproduction on reducing sugar consumption. Unit: $\mathrm{g} P$ / $g$ Rs

$Y_{P / P r}$ : Yield factor for bioproduction on soluble protein consumption. Unit: $\mathrm{g} \mathrm{P} / \mathrm{g} \mathrm{Pr}$ 


\section{Table 1.}

\begin{tabular}{lccc}
\hline & SP Chemical & SP Alcalase & SP Esperase \\
\hline Soluble protein $(\mathbf{g} / \mathbf{L})$ & $62.50 \pm 1.10$ & $57.02 \pm 1.60$ & $56.91 \pm 4.03$ \\
Reducing sugars $(\mathbf{g} / \mathbf{L})$ & $0.38 \pm 0.04$ & $0.29 \pm 0.08$ & $0.32 \pm 0.07$ \\
Total sugars $(\mathbf{g} / \mathbf{L})$ & $0.66 \pm 0.11$ & $0.53 \pm 0.10$ & $0.59 \pm 0.09$ \\
\hline
\end{tabular}


Table 2.

\begin{tabular}{|c|c|c|c|c|c|}
\hline & POLYNOMIAL EQUATIONS & $R_{\text {adj }}^{2}$ & $T_{\text {opt }}\left({ }^{\circ} \mathrm{C}\right)$ & pHopt & $Y_{\max }$ \\
\hline \multirow[t]{3}{*}{ Alcalase } & $H_{m}(\%)=17.46+4.88 p H-3.66 \mathrm{TpH}-8.07 \mathrm{~T}^{2}-3.57 \mathrm{pH}^{2}$ & 0.844 & 51.9 & 9.09 & $19.4 \%$ \\
\hline & $\operatorname{Pr}(\mathrm{g})=1.96+0.297 \mathrm{pH}+0.113 \mathrm{~T}-0.100 \mathrm{TpH}-0.724 \mathrm{~T}^{2}-0.240 \mathrm{pH}^{2}$ & 0.906 & 55.6 & 8.86 & $2.05 \mathrm{~g}$ \\
\hline & $\operatorname{Ch}(\%)=83.0+3.90 p H-3.46 T-11.04 T^{2}-4.77 p H^{2}$ & 0.743 & 52.2 & 8.58 & $84.1 \%$ \\
\hline \multirow[t]{4}{*}{ Esperase } & $H_{m}(\%)=16.38+2.15 T+5.22 p H-4.59 T^{2}-4.35 p H^{2}$ & 0.875 & 59.1 & 8.85 & $18.2 \%$ \\
\hline & $\operatorname{Pr}(\mathrm{g})=1.87+0.23 \mathrm{~T}+0.45 \mathrm{pH}-0.340 \mathrm{TpH}-0.269 \mathrm{~T}^{2}-0.283 \mathrm{pH}^{2}$ & 0.855 & 52.9 & 9.22 & $2.05 \mathrm{~g}$ \\
\hline & $C h(\%)=81.9+4.12 T+6.47 p H-5.92 T p H-5.36 T^{2}-3.75 p H^{2}$ & 0.847 & 52.1 & 9.41 & $84.8 \%$ \\
\hline & & $R_{\mathrm{adj}}^{2}$ & $T_{\text {opt }}\left({ }^{\circ} \mathrm{C}\right)$ & $\mathrm{NaOH}_{\text {opt }}(\mathrm{M})$ & $Y_{\max }$ \\
\hline \multirow[t]{2}{*}{ Chemical } & $\operatorname{Pr}(\mathrm{g})=1.92-0.13 \mathrm{~T}-0.068 \mathrm{NaOH}-0.059 \mathrm{~T}^{2}$ & 0.714 & 30.0 & 0.2 & $2.09 \mathrm{~g}$ \\
\hline & $\mathrm{Ch}(\%)=85.6-2.81 \mathrm{~T}+1.81 \mathrm{~T} \mathrm{NaOH}-1.64 \mathrm{~T}^{2}$ & 0.822 & 25.0 & 0.2 & $89.9 \%$ \\
\hline
\end{tabular}


Table 3.

\begin{tabular}{|c|c|c|c|c|}
\hline Parameters & SP Chemical & SP Alcalase & SP Esperase & MRS \\
\hline$X_{m}(g / L)$ & $1.33 \pm 0.06$ & $1.37 \pm 0.07$ & $1.30 \pm 0.05$ & $1.13 \pm 0.06$ \\
\hline$V_{x}\left(\mathrm{~g} \mathrm{~L}^{-1} \mathrm{~h}^{-1}\right)$ & $0.151 \pm 0.043$ & $0.112 \pm 0.029$ & $0.107 \pm 0.022$ & $0.107 \pm 0.031$ \\
\hline$\lambda_{x}(\mathrm{~h})$ & $5.80 \pm 1.43$ & $4.77 \pm 1.72$ & $5.35 \pm 1.35$ & $5.70 \pm 1.72$ \\
\hline$R^{2}$ & 0.994 & 0.994 & 0.996 & 0.993 \\
\hline$p$-value & $<0.0001$ & $<0.0001$ & $<0.0001$ & $<0.0001$ \\
\hline$Y_{X / R s}(\mathrm{~g} \mathrm{X/g}$ Rs) & 0.116 & 0.119 & 0.117 & 0.122 \\
\hline$Y_{X / P r}(g X / g P r)$ & 0.671 & 0.637 & 0.705 & 0.526 \\
\hline$B_{m}(\mathrm{BU} / \mathrm{mL})$ & $197.5 \pm 11.2$ & $205.3 \pm 12.8$ & $211.8 \pm 12.3$ & $257.6 \pm 15.2$ \\
\hline$V_{B}\left(B U \mathrm{~mL}^{-1} \mathrm{~h}^{-1}\right)$ & $11.48 \pm 2.43$ & $12.75 \pm 3.24$ & $14.59 \pm 3.06$ & $14.51 \pm 3.19$ \\
\hline$\lambda_{B}(\mathrm{~h})$ & $8.93 \pm 1.84$ & $7.41 \pm 2.09$ & $6.87 \pm 1.95$ & $7.57 \pm 1.97$ \\
\hline$R^{2}$ & 0.996 & 0.994 & 0.997 & 0.995 \\
\hline$p$-value & $<0.0001$ & $<0.0001$ & $<0.0001$ & $<0.0001$ \\
\hline$Y_{B / R s}(\mathrm{BU} / \mathrm{g} R \mathbf{R s})$ & 18695 & 18072 & 18962 & 27890 \\
\hline$Y_{B / P r}(\mathrm{BU} / \mathrm{g} \mathrm{Pr})$ & 108173 & 96841 & 114209 & 120116 \\
\hline $\operatorname{Lam}(\mathrm{g} / \mathrm{L})$ & $7.89 \pm 0.36$ & $7.86 \pm 0.26$ & $7.96 \pm 0.21$ & $7.36 \pm 0.24$ \\
\hline$V_{L a}\left(g_{L^{-1}}^{-1} \mathbf{h}^{-1}\right)$ & $0.709 \pm 0.173$ & $0.671 \pm 0.116$ & $0.809 \pm 0.124$ & $0.503 \pm 0.159$ \\
\hline$\lambda_{\mathrm{La}}(\mathrm{h})$ & $4.29 \pm 1.52$ & $4.11 \pm 1.13$ & $4.80 \pm 0.85$ & $4.44 \pm 0.94$ \\
\hline$R^{2}$ & 0.995 & 0.999 & 0.998 & 0.999 \\
\hline p-value & $<0.0001$ & $<0.0001$ & $<0.0001$ & $<0.0001$ \\
\hline$Y_{\text {La/Rs }}$ (g La/g Rs) & 0.749 & 0.702 & 0.706 & 0.807 \\
\hline$Y_{L a / P r}(\mathbf{g L a} / \mathbf{g ~ R s})$ & 4.332 & 3.759 & 4.253 & 3.476 \\
\hline$A_{m}(\mathrm{~g} / \mathrm{L})$ & $0.319 \pm 0.046$ & $0.367 \pm 0.036$ & $0.310 \pm 0.023$ & $0.228 \pm 0.023$ \\
\hline$V_{A}\left(g^{-1} h^{-1}\right)$ & $0.015 \pm 0.007$ & $0.021 \pm 0.009$ & $0.033 \pm 0.014$ & $0.012 \pm 0.004$ \\
\hline$\lambda_{A}(\mathrm{~h})$ & $5.17 \pm 4.99$ & 2.75 (NS) & $7.69 \pm 2.28$ & $10.34 \pm 3.10$ \\
\hline$R^{2}$ & 0.972 & 0.979 & 0.987 & 0.990 \\
\hline$p$-value & $<0.005$ & $<0.005$ & $<0.005$ & $<0.005$ \\
\hline$Y_{A / R s}(\mathrm{~g} \mathrm{~A} / \mathrm{g} R \mathbf{R s})$ & 0.030 & 0.032 & 0.028 & 0.024 \\
\hline$Y_{A / P r}(\mathbf{g ~ A} / \mathbf{g ~ R s})$ & 0.174 & 0.170 & 0.171 & 0.105 \\
\hline
\end{tabular}


Table 4.

\begin{tabular}{llcrrr}
\hline & POLYNOMIAL EQUATIONS & $R_{\text {adj }}^{2}$ & $t_{\text {opt }}(\mathrm{h})$ & $\mathbf{N a O H}_{\text {opt }}(\mathrm{M})$ & $\boldsymbol{Y}_{\max }$ \\
\hline Alcalase & $D D(\%)=88.0+11.21 t+26.93 \mathrm{NaOH}-13.48 t^{2}-13.23 \mathrm{NaOH}^{2}$ & 0.837 & 16.0 & 15.9 & $103 \%$ \\
Esperase & $D D(\%)=88.6+11.46 t+26.83 \mathrm{NaOH}+1.00 \mathrm{t} \mathrm{NaOH}-13.52 t^{2}-13.78 \mathrm{NaOH}^{2}$ & 0.837 & 15.9 & 16.1 & $103 \%$ \\
Chemical & $D D(\%)=88.8+11.23 t+26.13 \mathrm{NaOH}+1.25 \mathrm{tNaOH}-14.51 t^{2}-14.00 \mathrm{NaOH}^{2}$ & 0.815 & 16.2 & 16.0 & $103 \%$ \\
\hline
\end{tabular}


Table 5.

\begin{tabular}{lcc}
\hline & \multicolumn{2}{c}{ CS purity (\%) } \\
\cline { 2 - 3 } & Prec/Red step & UF/DF step \\
\hline Alkaline effluent Alcalase & $73.8 \pm 1.6$ & $89.1 \pm 1.5$ \\
Alkaline effluent Esperase & $75.2 \pm 1.8$ & $88.5 \pm 1.8$ \\
Alkaline effluent Chemical & $74.6 \pm 1.3$ & $89.6 \pm 2.4$ \\
NaOH solution & $83.9 \pm 0.8$ & $98.9 \pm 0.5$ \\
\hline
\end{tabular}




\section{An integral and sustainable valorization strategy of squid pen by-products}

\section{Electronic Supplementary Information}
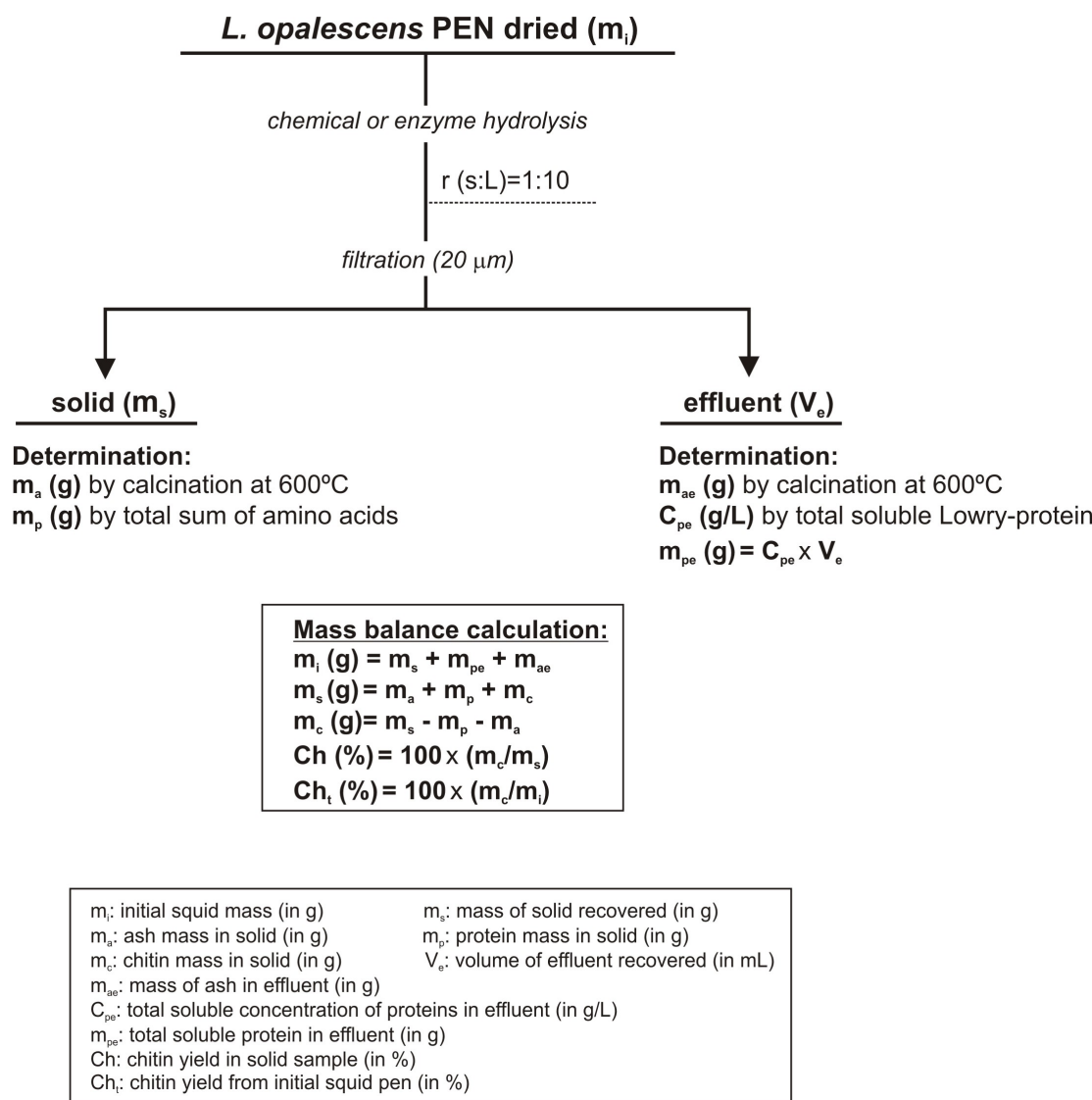

Figure S1. Flowchart describing the mass balances performed to calculate the yield of chitin $(\mathrm{Ch})$ obtained from $L$. opalescens pen processed by chemical or enzymatic treatments. 

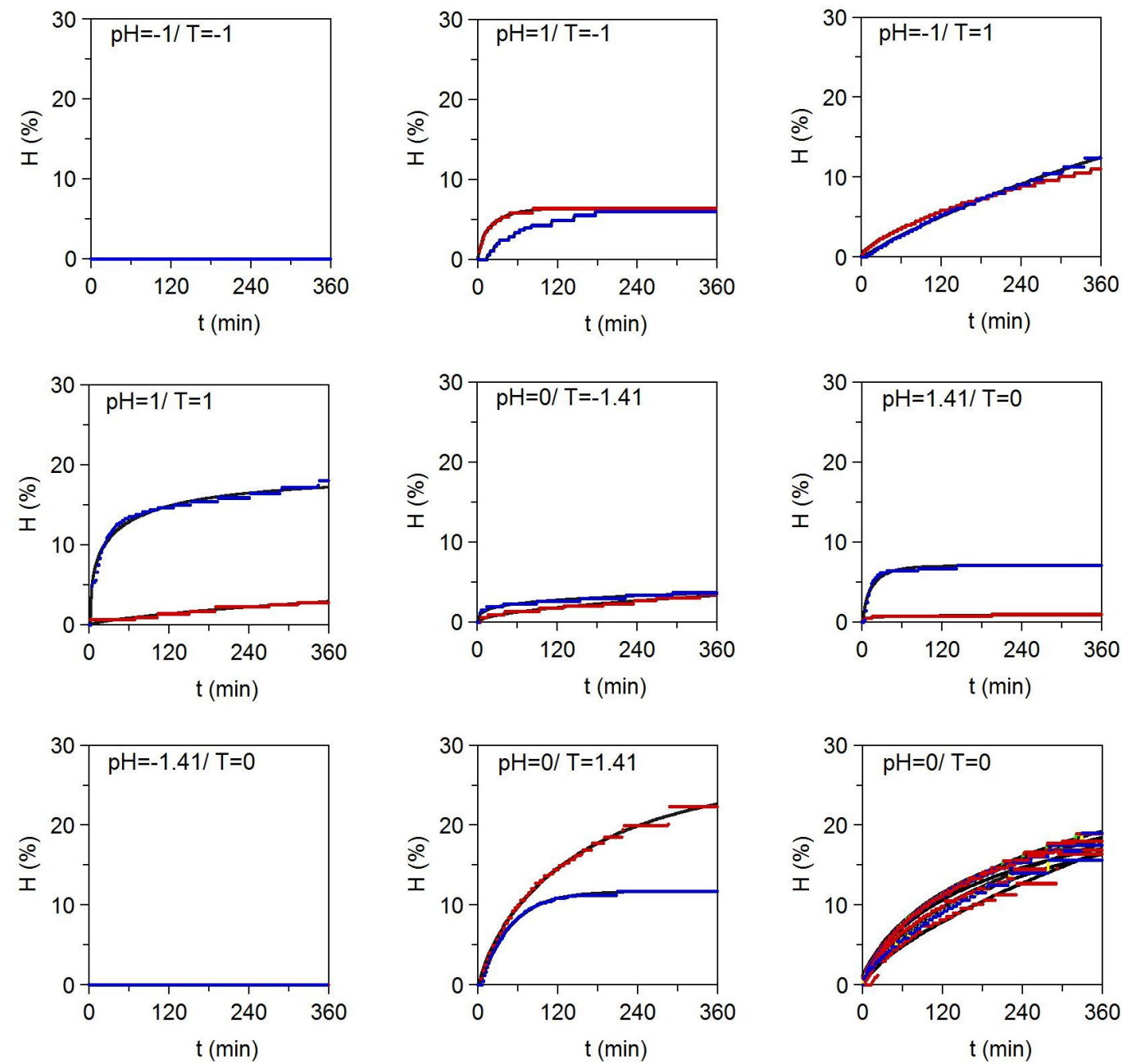

Figure S2. Kinetics of enzymatic proteolysis of L. opalescens endoskeletons using Alcalase (red) and Esperase (blue) working under the conditions summarized (as coded values) in Table S1 and Table S3. Experimental data (symbols) were fitted to Weibull equation [2] (black lines). Determination coefficients for such modelling were ranked as $R^{2}=0.777-0.999$ for Alcalase and $R^{2}=0.939-0.998$ for Esperase. 

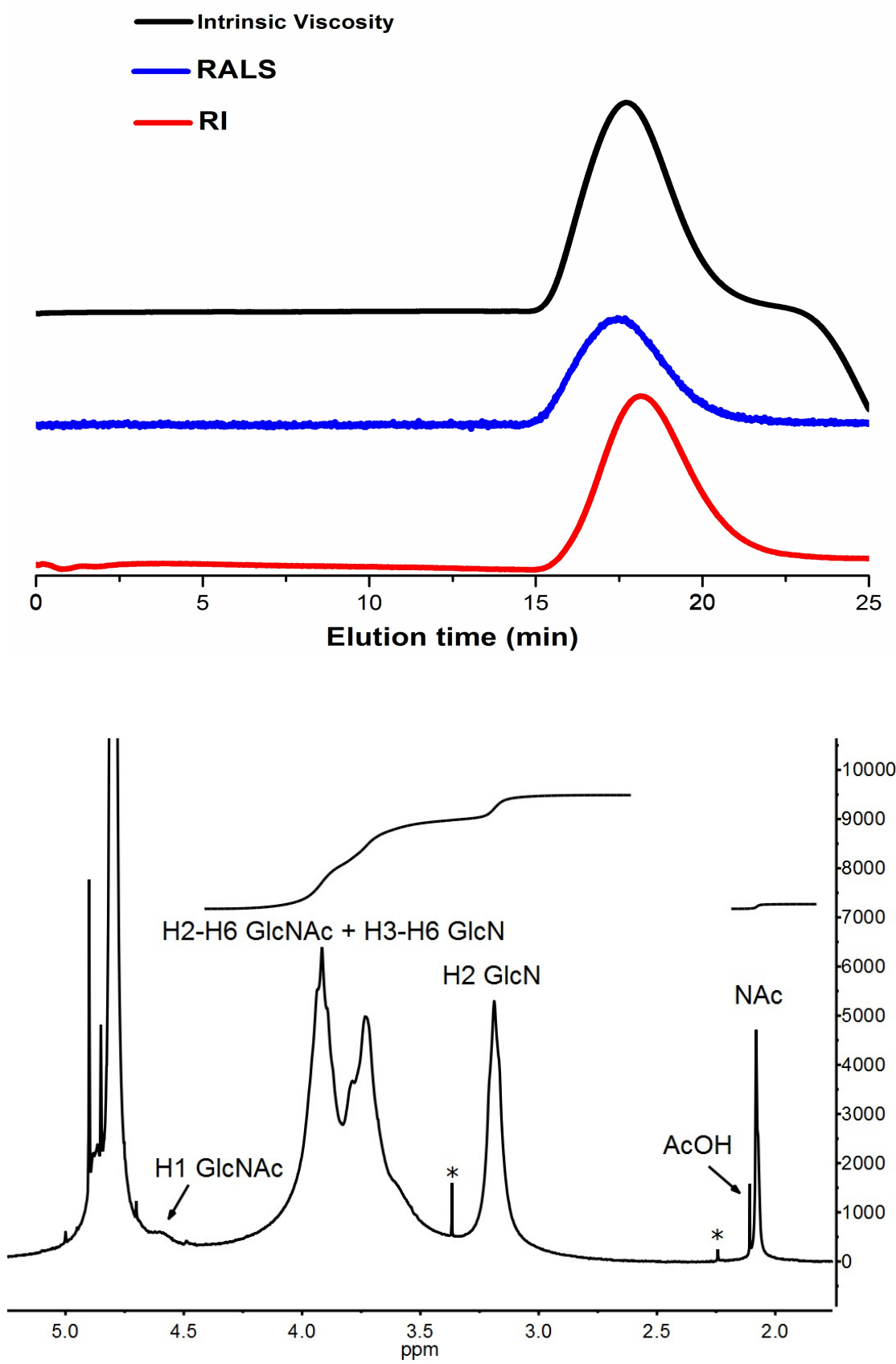

Figure S3. (Top) Gel permeation chromatography eluogram (red line refraction index detector, blue line - right angle light scattering detector, black line - viscometer) and (bottom) NMR spectrum of chitosan with molecular weight of $111 \mathrm{kDa}$ and degree of deacetylation of $92 \%$. Deproteinization was carried out with $\mathrm{NaOH}$ followed by deacetylation with $12.5 \mathrm{M} \mathrm{NaOH}$ for $12.5 \mathrm{~h}$. Solvent signals. 
Table S1. Experimental domain and codification of independent variables in the second order rotatable designs developed for chitin and chitosan production from $L$. opalescens endoskeletons.

\begin{tabular}{|c|c|c|c|c|c|c|c|c|}
\hline \multirow[b]{5}{*}{ Coded values } & \multicolumn{8}{|c|}{ Natural values } \\
\hline & \multicolumn{6}{|c|}{ CHITIN } & \multirow{2}{*}{\multicolumn{2}{|c|}{$\begin{array}{l}\text { CHITOSAN } \\
\text { Chemical }\end{array}$}} \\
\hline & \multicolumn{2}{|c|}{ Chemical } & \multicolumn{4}{|c|}{ Enzymatic } & & \\
\hline & \multirow[b]{2}{*}{$\mathrm{NaOH}(\mathrm{M})$} & \multirow[b]{2}{*}{$\mathrm{T}\left({ }^{\circ} \mathrm{C}\right)$} & \multicolumn{2}{|c|}{ Alcalase } & \multicolumn{2}{|c|}{ Esperase } & \multirow[b]{2}{*}{$\mathrm{NaOH}(\mathrm{M})$} & \multirow[b]{2}{*}{$t(h)$} \\
\hline & & & $\mathrm{pH}$ & $\mathrm{T}\left({ }^{\circ} \mathrm{C}\right)$ & $\mathrm{pH}$ & $\mathrm{T}\left({ }^{\circ} \mathrm{C}\right)$ & & \\
\hline-1.41 & 0.20 & 25.0 & 6.0 & 30.0 & 6.0 & 30.0 & 7.5 & 1.0 \\
\hline-1 & 0.46 & 32.3 & 6.6 & 37.3 & 6.6 & 37.3 & 9.0 & 4.4 \\
\hline 0 & 1.10 & 50.0 & 8.0 & 55.0 & 8.0 & 55.0 & 12.5 & 12.5 \\
\hline+1 & 1.74 & 67.7 & 9.4 & 72.7 & 9.4 & 72.7 & 16.0 & 20.6 \\
\hline+1.41 & 2.00 & 75.0 & 10.0 & 80.0 & 10.0 & 80.0 & 17.5 & 24.0 \\
\hline \multicolumn{5}{|c|}{$\begin{array}{l}\text { Codification: } V_{c}=\left(V_{n}-V_{0}\right) / \Delta V_{n} \\
V_{n}=\text { natural value of the variable to codify } \\
V_{0}=\text { natural value in the centre of the domain }\end{array}$} & \multicolumn{4}{|c|}{$\begin{array}{l}\text { Decodification: } V_{n}=V_{0}+\left(\Delta V_{n} \times V_{c}\right) \\
\Delta V_{n}=\text { increment of } V_{n} \text { for unit of } V_{c} \\
V_{c}=\text { codified value of the variable }\end{array}$} \\
\hline
\end{tabular}


Table S2. Amino acids present (as \%) on the effluents (squid peptones, SP) obtained in the optimal conditions calculated (Table 1) for chitin production from $L$. opalescens by-products. The error associated is the confidence intervals for $\mathrm{n}=2$ and $\alpha=0.05$.

\begin{tabular}{lccc}
\hline Amino acids & SP Chemical & SP Alcalase & SP Esperase \\
\hline Aspartic acid & $8.91 \pm 0.06$ & $8.76 \pm 0.14$ & $8.67 \pm 0.31$ \\
Threonine & $3.20 \pm 0.32$ & $3.73 \pm 0.30$ & $3.45 \pm 0.23$ \\
Serine & $5.01 \pm 0.29$ & $5.31 \pm 0.09$ & $5.32 \pm 0.43$ \\
Glutamic acid & $5.67 \pm 0.35$ & $5.55 \pm 0.16$ & $5.32 \pm 0.33$ \\
Glycine & $14.38 \pm 1.19$ & $12.92 \pm 0.40$ & $13.03 \pm 0.28$ \\
Alanine & $15.88 \pm 0.84$ & $16.17 \pm 0.58$ & $16.11 \pm 0.42$ \\
Cysteine & $0.73 \pm 0.09$ & $0.98 \pm 0.11$ & $0.95 \pm 0.21$ \\
Valine & $4.32 \pm 0.22$ & $5.14 \pm 0.28$ & $5.08 \pm 0.54$ \\
Methionine & $1.68 \pm 0.25$ & $1.60 \pm 0.13$ & $2.16 \pm 0.16$ \\
Isoleucine & $1.59 \pm 0.11$ & $1.65 \pm 0.14$ & $1.90 \pm 0.23$ \\
Leucine & $6.16 \pm 0.68$ & $5.88 \pm 0.49$ & $5.69 \pm 0.38$ \\
Norleucine & $3.55 \pm 1.10$ & $2.94 \pm 0.55$ & $2.85 \pm 0.64$ \\
Tyrosine & $5.81 \pm 1.01$ & $6.02 \pm 0.54$ & $6.55 \pm 0.43$ \\
Phenylalanine & $3.09 \pm 0.09$ & $2.82 \pm 0.49$ & $2.39 \pm 0.53$ \\
Histidine & $6.13 \pm 0.47$ & $6.00 \pm 0.93$ & $5.61 \pm 0.40$ \\
Lysine & $2.52 \pm 0.19$ & $3.03 \pm 0.24$ & $3.17 \pm 0.29$ \\
Arginine & $1.28 \pm 0.26$ & $1.45 \pm 0.16$ & $1.76 \pm 0.31$ \\
Hydroxyproline & - & - & - \\
Proline & $10.10 \pm 0.43$ & $10.02 \pm 0.39$ & $9.99 \pm 0.47$ \\
\hline
\end{tabular}


Table S3. Composition of culture media for $P$. acidilactici (in g/L). SP: squid peptone.

\begin{tabular}{lcccc}
\hline \multicolumn{1}{c}{ INGREDIENTS } & Medium A & Medium B & Medium C & MRS \\
\hline Glucose & 20 & 20 & 20 & 20 \\
Yeast extract & 4 & 4 & 4 & 4 \\
Sodium acetate & 5 & 5 & 5 & 5 \\
Ammonium citrate & 2 & 2 & 2 & 2 \\
$\mathrm{~K}_{2} \mathrm{HPO}_{4}$ & 2 & 2 & 2 & 2 \\
$\mathrm{MgSO}_{4}$ & 0.2 & 0.2 & 0.2 & 0.2 \\
$\mathrm{MnSO}_{4}$ & 0.05 & 0.05 & 0.05 & 0.05 \\
Tween 80 & 1 & 1 & 1 & 1 \\
Meat extract & - & - & - & 8 \\
Bactopeptone & - & - & - & 10 \\
SP from L. opalescens pen as protein-Lowry & 10 & 10 & 10 & - \\
\hline
\end{tabular}

Medium A: formulated with SP Chemical. Medium B: formulated with SP Alcalase. Medium C: formulated with SP Esperase. 
Table S4. Numerical estimations corresponding to the maximum hydrolysis $\left(H_{m}\right)$ parameter obtained from Weibull equation (3) in each experimental condition studied. Experimental data of chitin purity $(\mathrm{Ch})$ in the recovered solid samples and the protein content $(P r)$ released to effluents are also described. Independent variables are expressed in natural values in brackets. Numerical values of the $H_{m}$ parameter are shown with their associated confidence intervals. NHD: non hydrolysis detected.

\begin{tabular}{|c|c|c|c|c|}
\hline & Experimental conditions & $H_{m}(\%)$ & $\operatorname{Ch}(\%)$ & $\operatorname{Pr}(\mathrm{g})$ \\
\hline \multirow{13}{*}{ Alcalase } & T:-1 (37.3으) / pH:-1 (6.6) & NHD & 66.74 & 0.53 \\
\hline & $\mathrm{T}: 1\left(72.7^{\circ} \mathrm{C}\right) / \mathrm{pH}:-1(6.6)$ & $6.40 \pm 0.02$ & 58.77 & 0.99 \\
\hline & $\mathrm{T}:-1\left(37.3^{\circ} \mathrm{C}\right) / \mathrm{pH}: 1(9.4)$ & $11.0 \pm 7.2$ & 71.94 & 1.02 \\
\hline & $\mathrm{T}: 1\left(72.7^{\circ} \mathrm{C}\right) / \mathrm{pH}: 1$ (9.4) & $2.80(\mathrm{NS})$ & 54.14 & 1.08 \\
\hline & $\mathrm{T}:-1.41\left(30.0^{\circ} \mathrm{C}\right) / \mathrm{pH}: 0(8.0)$ & 3.45 (NS) & 66.00 & 0.47 \\
\hline & $\mathrm{T}: 1.41\left(80.0^{\circ} \mathrm{C}\right) / \mathrm{pH}: 0(8.0)$ & 0.95 (NS) & 64.68 & 0.75 \\
\hline & $\mathrm{T}: 0\left(55.0^{\circ} \mathrm{C}\right) / \mathrm{pH}:-1.41(6.0)$ & NHD & 67.00 & 0.94 \\
\hline & $\mathrm{T}: 0\left(55.0^{\circ} \mathrm{C}\right) / \mathrm{pH}: 1.41(10.0)$ & $22.3 \pm 0.9$ & 88.63 & 2.20 \\
\hline & $\mathrm{T}: 0\left(55.0^{\circ} \mathrm{C}\right) / \mathrm{pH}: 0(8.0)$ & $16.9 \pm 9.1$ & 81.44 & 1.86 \\
\hline & $\mathrm{T}: 0\left(55.0^{\circ} \mathrm{C}\right) / \mathrm{pH}: 0(8.0)$ & $16.4(\mathrm{NS})$ & 87.93 & 1.94 \\
\hline & $\mathrm{T}: 0\left(55.0^{\circ} \mathrm{C}\right) / \mathrm{pH}: 0(8.0)$ & $17.0 \pm 0.5$ & 82.00 & 1.97 \\
\hline & $\mathrm{T}: 0\left(55.0^{\circ} \mathrm{C}\right) / \mathrm{pH}: 0(8.0)$ & $19.0 \pm 2.0$ & 80.00 & 1.97 \\
\hline & $\mathrm{T}: 0\left(55.0^{\circ} \mathrm{C}\right) / \mathrm{pH}: 0(8.0)$ & $18.0 \pm 1.0$ & 83.47 & 2.05 \\
\hline \multirow{13}{*}{ Esperase } & T:-1 (37.3으) / pH:-1 (6.6) & NHD & 70.61 & 0.59 \\
\hline & $\mathrm{T}: 1\left(72.7^{\circ} \mathrm{C}\right) / \mathrm{pH}:-1(6.6)$ & $6.10 \pm 0.06$ & 77.00 & 1.66 \\
\hline & $\mathrm{T}:-1\left(37.3^{\circ} \mathrm{C}\right) / \mathrm{pH}: 1(9.4)$ & $12.4 \pm 7.2$ & 85.29 & 2.14 \\
\hline & $\mathrm{T}: 1\left(72.7^{\circ} \mathrm{C}\right) / \mathrm{pH}: 1(9.4)$ & $18.7 \pm 0.6$ & 78.00 & 1.85 \\
\hline & $\mathrm{T}:-1.41\left(30.0^{\circ} \mathrm{C}\right) / \mathrm{pH}: 0(8.0)$ & $3.67 \pm 1.31$ & 60.40 & 0.74 \\
\hline & $\mathrm{T}: 1.41\left(80.0^{\circ} \mathrm{C}\right) / \mathrm{pH}: 0(8.0)$ & $7.03 \pm 0.05$ & 77.23 & 1.47 \\
\hline & $\mathrm{T}: 0\left(55.0^{\circ} \mathrm{C}\right) / \mathrm{pH}:-1.41(6.0)$ & NHD & 62.83 & 0.44 \\
\hline & $\mathrm{T}: 0\left(55.0^{\circ} \mathrm{C}\right) / \mathrm{pH}: 1.41(10.0)$ & $11.7 \pm 0.04$ & 81.23 & 1.72 \\
\hline & $\mathrm{T}: 0\left(55.0^{\circ} \mathrm{C}\right) / \mathrm{pH}: 0(8.0)$ & $16.1 \pm 0.01$ & 80.25 & 2.19 \\
\hline & $\mathrm{T}: 0\left(55.0^{\circ} \mathrm{C}\right) / \mathrm{pH}: 0(8.0)$ & $16.7 \pm 0.1$ & 81.52 & 1.86 \\
\hline & $\mathrm{T}: 0\left(55.0^{\circ} \mathrm{C}\right) / \mathrm{pH}: 0(8.0)$ & $17.4 \pm 0.6$ & 84.12 & 1.77 \\
\hline & $\mathrm{T}: 0\left(55.0^{\circ} \mathrm{C}\right) / \mathrm{pH}: 0(8.0)$ & $16.0 \pm 2.9$ & 80.52 & 1.77 \\
\hline & $\mathrm{T}: 0\left(55.0^{\circ} \mathrm{C}\right) / \mathrm{pH}: 0(8.0)$ & $15.6 \pm 1.5$ & 83.21 & 1.79 \\
\hline \multirow{13}{*}{ Chemical } & $\mathrm{T}:-1\left(32.3^{\circ} \mathrm{C}\right) / \mathrm{NaOH}:-1(0.46 \mathrm{M})$ & - & 88.22 & 2.09 \\
\hline & $\mathrm{T}: 1\left(67.7^{\circ} \mathrm{C}\right) / \mathrm{NaOH}:-1(0.46 \mathrm{M})$ & - & 77.80 & 1.93 \\
\hline & $\mathrm{T}:-1\left(32.3^{\circ} \mathrm{C}\right) / \mathrm{NaOH}: 1(1.74 \mathrm{M})$ & - & 86.55 & 1.92 \\
\hline & $\mathrm{T}: 1\left(67.7^{\circ} \mathrm{C}\right) / \mathrm{NaOH}: 1(1.74 \mathrm{M})$ & - & 83.39 & 1.80 \\
\hline & $\mathrm{T}:-1.41\left(25.0^{\circ} \mathrm{C}\right) / \mathrm{NaOH}: 0(1.1 \mathrm{M})$ & - & 85.90 & 2.01 \\
\hline & $\mathrm{T}: 1.41\left(75.0^{\circ} \mathrm{C}\right) / \mathrm{NaOH}: 0$ (1.1 M) & - & 79.64 & 1.45 \\
\hline & $\mathrm{T}: 0\left(50.0^{\circ} \mathrm{C}\right) / \mathrm{NaOH}:-1.41(0.2 \mathrm{M})$ & - & 88.07 & 1.95 \\
\hline & $\mathrm{T}: 0\left(50.0^{\circ} \mathrm{C}\right) / \mathrm{NaOH}: 1.41(2 \mathrm{M})$ & - & 85.93 & 1.77 \\
\hline & $\mathrm{T}: 0\left(50.0^{\circ} \mathrm{C}\right) / \mathrm{NaOH}: 0(1.1 \mathrm{M})$ & - & 84.87 & 1.90 \\
\hline & $\mathrm{T}: 0\left(50.0^{\circ} \mathrm{C}\right) / \mathrm{NaOH}: 0(1.1 \mathrm{M})$ & - & 85.11 & 1.96 \\
\hline & $\mathrm{T}: 0\left(50.0^{\circ} \mathrm{C}\right) / \mathrm{NaOH}: 0(1.1 \mathrm{M})$ & - & 85.56 & 1.87 \\
\hline & $\mathrm{T}: 0\left(50.0^{\circ} \mathrm{C}\right) / \mathrm{NaOH}: 0(1.1 \mathrm{M})$ & - & 86.05 & 1.89 \\
\hline & $\mathrm{T}: 0\left(50.0^{\circ} \mathrm{C}\right) / \mathrm{NaOH}: 0(1.1 \mathrm{M})$ & - & 86.34 & 1.95 \\
\hline
\end{tabular}

